Portland State University

PDXScholar

$1-1-1983$

\title{
A mechanistic study of the electrochemical formation of CdS CdSe semiconducting films
}

Mario Aparicio-Razo

Portland State University

Follow this and additional works at: https://pdxscholar.library.pdx.edu/open_access_etds Let us know how access to this document benefits you.

\section{Recommended Citation}

Aparicio-Razo, Mario, "A mechanistic study of the electrochemical formation of CdS CdSe semiconducting films" (1983). Dissertations and Theses. Paper 448.

https://doi.org/10.15760/etd.448

This Dissertation is brought to you for free and open access. It has been accepted for inclusion in Dissertations and Theses by an authorized administrator of PDXScholar. Please contact us if we can make this document more accessible: pdxscholar@pdx.edu. 
A MECHANISTIC STUDY OF THE ELECTROCHEMICAL

FORMATION OF CdS/CdSe SEMICONDUCTING FILMS

by

MARIO APARICIO-RAZO

A dissertation submitted in partial fulfillment of the requirements for the degree

DOCTOR OF PHILOSOPHY

in

ENVIRONMENTAL SCIENCES AND RESOURCES: CHEMISTRY

\author{
Portland State University \\ (C) 1983 Mario Aparicio-Razo
}


TO THE OFFICE OF GRADUATE STUDIES AND RESEARCH:

The members of the Committee approve the dissertation of

Mario Aparicio-Razo presented May 13, 1983.

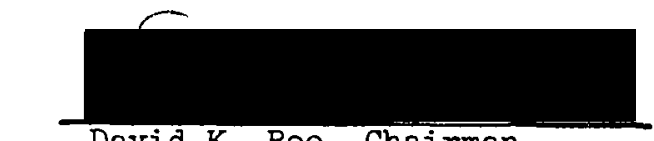

David K. Roe, Chairman

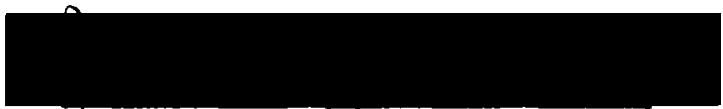

Jonathan J. A. Aramson

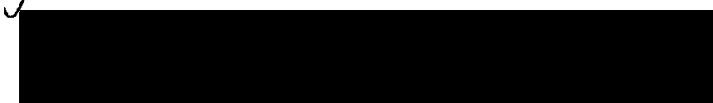

Nicholas G. Eror
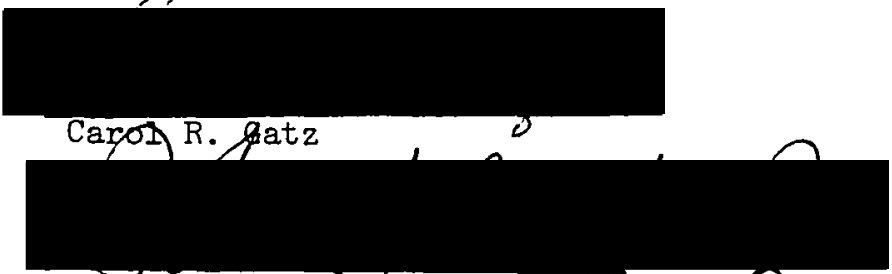

Joht G. Rueter

APPKOVED:

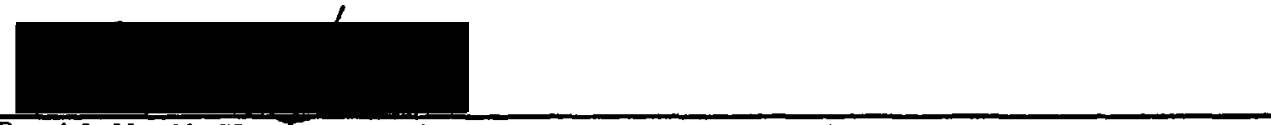

David W. McClure, Head, Department of Chemistry .

Robert 0.'Tinnin, Director, Environmental Sciences and Resources. 1 Then, Director,

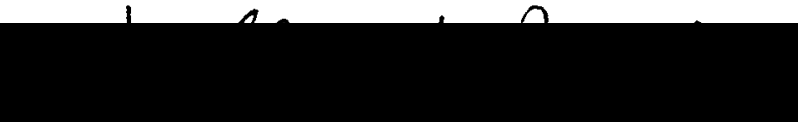

William'W. Paudler, Dean, College of Liberal Arts and Sciences.

Stanley E. Rauch, Dean of Graduate Studies and Research. 
AN ABSTRACT OF THE DISSERTATION OF Mario Aparicio-Razo for the

Doctor of Philosophy in Environmental Sciences and Resources: Chemistry presented May 13, 1983.

Title: A Mechanistic Study of the Electrochemical Formation of CdS/CdSe Semiconducting Films

APPROVED BY MEMBERS OF THE DISSERTATION COMMITTEE:

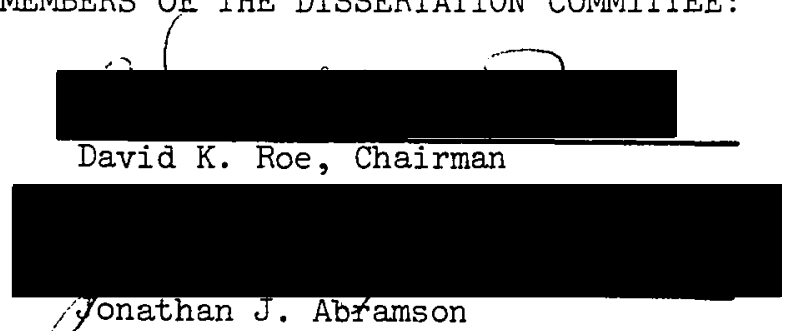

Jonathan J. Abramson
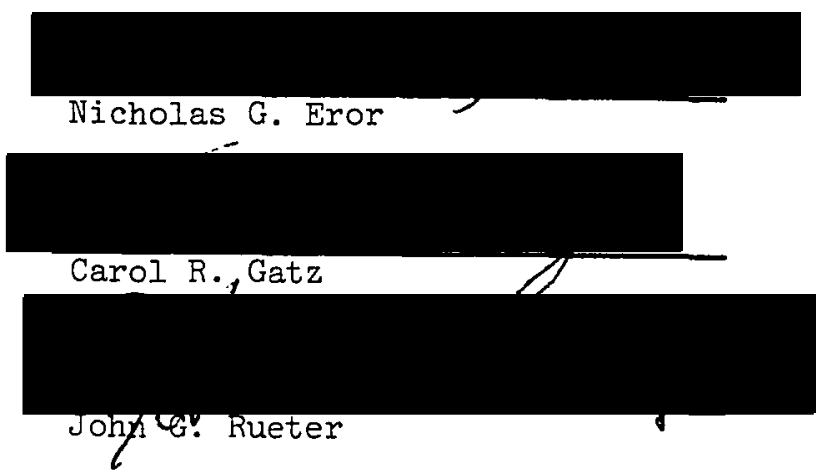

Cadmium sulfide and cadmium selenide are important materials for applications such as photoconductive cells, photovoltaic cells and other electrooptical devices. Generally, these devices use single crystals. However, reasonable efficiencies have been observed by using polycrystalline films on conducting substrates, which are easier to make and pro- 
vide considerable savings on materials and energy.

Polycrystalline CdS/CdSe films have been made by sputtering and solution spraying, compound evaporation, chemical vapor deposition, and many others. A recent technique involves the electrochemical deposition of CdS and CdSe from nonaqueous solvents. Preparation of these films is based upon the cathodic deposition from a nonaqueous solution of a cadmium salt and elemental sulfur and/or selenium. Although the technique is simple, no mechanistic information is known to optimize the conditions in which films of controlled stoichiometry, doping and crystallinity are made.

This research has the purpose to understand the mechanism of the formation of polycrystalline films of CdS and CdSe by electrochemical deposition in dimethylsulfoxide. This approach to the problem makes use of electrochemical techniques such as rotating ring disc electrode, linear scan voltammetry, high pressure liquid chromatography coupled with ultraviolet and electrochemical detection.

By the rotating ring disc electrode technique, we have studied the kinetic parameters for the reduction of sulfur, selenium, cadmium, and the electrochemical formation of $\mathrm{CdS}$ and CdSe for temperatures from 25 $100^{\circ} \mathrm{C}$. The results show that rates of initial electron transfer for the reduction of these species are moderately rapid, and secondly, that the reverse reaction is irreversible and involves additional steps. Studies of solubility of selenium with temperature reveal that its solubility is enhanced by the addition of sulfur. Understanding the electrochemical behavior of sulfur-selenium mixtures is of great importance to produce mixed semiconductive films with more adequate bandgaps for use with so- 
lar spectrum. Electrochemistry of sulfur-selenium mixtures are no different from that of sulfur alone. High pressure liquid chromatography separations with spectroscopic and electrochemical detectors have shown that sulfur solutions contain $S_{6}$ and $S_{7}$ fractions which are not electrochemically active. 


\section{ACKINOWLEDGEMENTS}

I would like to thank all the members of my committee for their time and criticisms. Special thanks are due Professor David Roe for his patience and encouragement throughout this project.

Appreciation is extended to Professor Bruce Brown for his friendship and for the use of his LSQI program; to Dennis Clark and Mrs. Betty Cook, who were always helpful in obtaining the chemicals needed; to Rudolph Zupan, Garo Arakelian, and Brian McLaughlin, who helped make and assemble the equipment; to Peg Pankratz, who straightened out administrative problems; to Karen Brown, who typed the manuscript; to Karen D'Arcy for her critical suggestings; and to all my friends.

I thank my parents, Mario and Angelina, for their spiritual support; to Dianne, who somehow endured the long hours and frustration: and finally, to my boys, David and Michael, whose smiles brightened my days. 
TABLE OF CONTENTS

Page

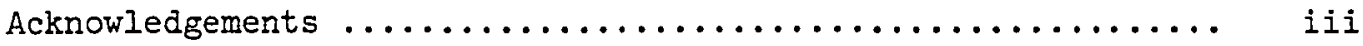

List of Tables $\ldots \ldots \ldots \ldots \ldots \ldots \ldots \ldots \ldots \ldots \ldots \ldots \ldots \ldots \ldots \ldots \ldots \ldots$ vi

List of Figures $\ldots \ldots \ldots \ldots \ldots \ldots \ldots \ldots \ldots \ldots \ldots \ldots \ldots \ldots \ldots \ldots \ldots$ vii

CHAPTER

I INTRODUCTION $\ldots \ldots \ldots \ldots \ldots \ldots \ldots \ldots \ldots \ldots \ldots \ldots \ldots$

II EXPERIMENTAL $\ldots \ldots \ldots \ldots \ldots \ldots \ldots \ldots \ldots \ldots \ldots \ldots \ldots \ldots \ldots \ldots \ldots$

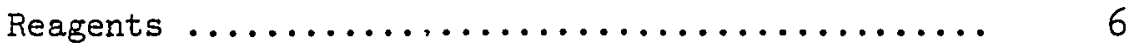

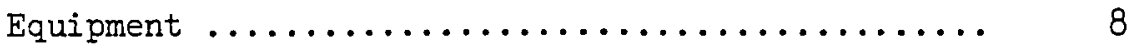

EXPERIMENTAL METHODS AND PROCEDURES $\ldots \ldots \ldots \ldots \ldots \ldots .10$

Determination of the Solubility of Selenium in

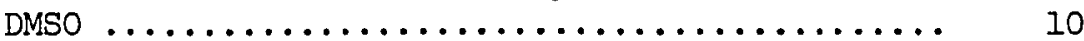

HPLC Analysis $\ldots \ldots \ldots \ldots \ldots \ldots \ldots \ldots \ldots \ldots \ldots . \ldots \ldots \ldots$

Reaction of Cadmium with Sulfur and/or Selenium .. 12

Supporting Electrolytes .................. 12

Electrodes Pretreatment .................... 14

The Rotating Ring Disc Electrode ............. 14

Collection Efficiency for the RRDE ............ 17

Reactions at the RRDE ................... 17

Kinetic currents and diffusion coefficients ...... 18

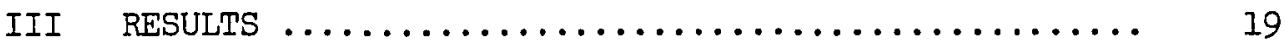

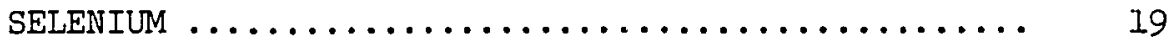

Solubility of Selenium in DMSO ...................... 19

Electrochemistry of Selenium at a RRDE ......... 20

HPLC Separation of Selenium Solutions in DMSO .... 26

Reaction Between Cadmium and Selenium .......... 29

SULFUR $\ldots \ldots \ldots \ldots \ldots \ldots \ldots \ldots \ldots \ldots \ldots \ldots \ldots \ldots \ldots \ldots \ldots \ldots \ldots, \quad 31$

Electrochemistry of Sulfur at a RRDE .......... 31 
Ring Measurements ..................... 37

HPLC Separation of Sulfur Solutions ........... 37

Electrochemistry of $S_{6}, S_{7}$, and $S_{8}$ in a flow cell 42

Reaction of $S_{x}$ with metallic cadmium .......... 46

CADMIUM $\ldots \ldots \ldots \ldots \ldots \ldots \ldots \ldots \ldots \ldots \ldots \ldots \ldots \ldots \ldots$

Electrochemistry of Cadmium ............... 48

Electrochemical Formation of CdS and CdSe ....... 48

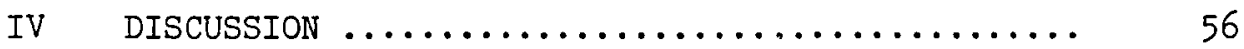

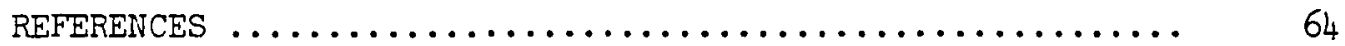


I Rate Constants for the Reduction of Selenium ......... 26

II $\quad H P L C$ Separation of Selenium ................... 26

II Reaction of $\mathrm{Se}_{\mathrm{x}}$ with Metallic Cadmium ............. 29

IV Intercept Values of $(A C / i)$ for Sulfur Reduction x $10^{3} \ldots 32$

V Heterogeneous Rate Constants for the Reduction of Sulfur. 32

VI HPLC Separation of Sulfur in DMSO ............... 41

VII Reaction of $s_{x}$ with Metallic Cadmium .............. 46

VII Heterogeneous Rate Constants for the Reduction of Cadmium 48 
vii

\section{LIST OF FIGURES}

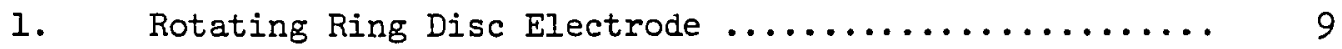

2. Electrochemical Cells for RRDE Studies ............ 11

3. Dual Potentiostat for RRDE Measurements .......... 13

4. Collection Efficiency $\ldots \ldots \ldots \ldots \ldots \ldots \ldots \ldots \ldots \ldots \ldots \ldots \ldots \ldots \ldots \ldots$

5. Solubility of Selenium as a Function of Temperature .. 20

6. Increase of Selenium Solubility in DMSO in the

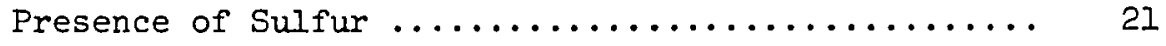

7. Reduction of Selenium at a Rotating Ring Disc

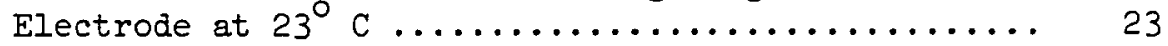

8. Effect of $w^{\frac{1}{2}}$ on Disc Currents for Selenium at

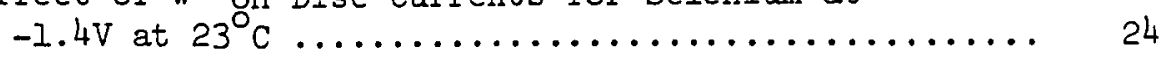

9. Temperature Effect on Disc Currents for Selenium ..... 25

10. $-\log k$ Versus $-\log C$ for Selelnium $\ldots \ldots \ldots \ldots \ldots \ldots$

11. HPLC Separation of Selenium in DMSO ............ 28

12. HPLC Chromatograms of a Satuated Selenium Solution

a) Before Reaction b), c) After Reaction with 50 and $100 \mathrm{mg}$ of Metallic Cadmium .............. 30

13. Reduction of Sulfur at a Rotating Ring Disc Electrode

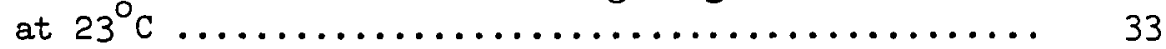

14. Effect of $w^{\frac{1}{2}}$ on Disc Currents for $s_{8}$ at $23^{\circ} \ldots \ldots \ldots . . . .34$

15. Effect of the Disc Potentials on the Kinetic Currents 35

16. Temperature Effect on Disc Currents for $S_{8} \ldots \ldots \ldots 36$

17. $\quad-\log k$ Versus $-\log C$ for Sulfur $\ldots \ldots \ldots \ldots \ldots \ldots \ldots$ 
18. Ring Scans during the Reduction of Sulfur at the Disc Electrode at $23^{\circ}$ and $75^{\circ} \mathrm{C} \ldots \ldots \ldots \ldots \ldots \ldots \ldots$

19. Effect of $w^{\frac{1}{2}}$ on Disc and Ring Currents at $23^{\circ} \ldots \ldots .40$

20. HPLC Separation of Sulfur in DMSO $\ldots \ldots \ldots \ldots \ldots \ldots . . . . .41$

21. UV Spectra for $S_{6}, S_{7}$ and $S_{8}$ from HPLC Data ...... 43

22. Current-time curve of $S_{6}, S_{7}$, and $S_{8}$ in a Flow CelI compared to UV-detector response .............. 44

23. Reduction of $S_{8}$ in Flow Cell $\ldots \ldots \ldots \ldots \ldots \ldots \ldots . \ldots \ldots$

24. HPLC Chromatogram for the Reaction of Cadmium and

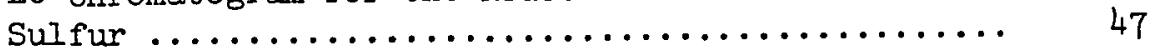

25. Reduction of Cadmium (II) at a RRDE at $1000 \mathrm{rpm} . . .49$

26. Effect of $w^{\frac{1}{2}}$ on Disc Currents for Cadmium ......... 50

27. Electrochemical Formation of CaSe ............. 52

28. Potential Shift on the Anodic Peak of Cadmium upon addition of Selenium .................... 53

29. Total Charge in the Stripping of CaSe ad a Function of Selenium Concentration ................... 54

30. Soluble Products ( $\mathrm{b}^{\prime}$ ) at the Ring Electrode During the Electrochemical Deposition of CdSe at the Disc 55

31 HPLC Separation of a Mixture of Saturated Selenium and Sulfur $1 \times 10^{-7} \mathrm{~F}$. in DMSO................ 63 


\section{CHAPTER I}

\section{INTRODUCTION}

Cadmium sulfide and cadmium selenide are important materials for applications such as photoconductive cells, photovoltaic cells, photoelectrochemical cells, and other electrooptical devices (1-6). Generally, these devices use single crystals. However, reasonable efficiencies have been observed by using polycrystalline films on conducting substrates.

Thus far, these films have been formed by vapor deposition techniques (7-9), heterogeneous precipitation from solution (10-14), flash evaporation (15), press sintered $(16-17)$, aqueous and paste painting (18-20), electrochemical codeposition (21-22), anodization of a metal in sulfur or selenium solutions (23), cathodically deposited from aqueous solutions (24-28), and even electrophoretically (29). Heat treatment followed almost all of the methods used.

The purpose of this research is to try to understand the mechanism of formation of CaS and CaSe by electrochemical deposition from nonaqueous solvents, in particular with dimethylsulfoxide (DMSO) as the solvent. Preparation of these films is based upon cathodic deposition from a nonaqueous solution of a cadmium salt and elemental sulfur and/or selenium. The solution may contain an inert electrolyte, such as sodium tetrafluoroborate (TFB) to improve electrolytic conduction. 
Cathodic electrodeposition of metal chalcogenides has been the object of the work of two different groups $(30,31)$. They have reported deposits that produce photopotentials in aqueous sulfur sulfide solutions, and that doping agents could be incorporated in the films during the electrochemical process.

Baranski and Fawcett (31-33) reported films of CdS, CdSe, CdSCdSe, $\mathrm{PbS}, \mathrm{Cu}_{2} \mathrm{~S}$, and many others electrodeposited on $\mathrm{Pt}$, Au, stainless steel, $\mathrm{Ni}, \mathrm{Zn}$, and glass covered with $\mathrm{SnO}_{2}$ from elemental chalcogenide, and the metal salt solutions from solvents such as DMSO, DMF and ethyl glycol. The overall reaction reported is

$$
\mathrm{M}^{++}+\mathrm{X}+2 \mathrm{e}^{-} \longrightarrow \mathrm{MX}
$$

They propose a mechanism in which freshly electrodeposited metal monolayer reacts with the dissolved chalcogenide. X-ray diffractometer patterns compare favorably with those for $\beta$-CdS. A Rutherford spectrum for $\alpha$-particles back-scattered from the CaS deposits gave two peaks, one for $\mathrm{Cd}$ and one for S. From these peaks the film composition was estimated to be uniform in depth with a sulfur to cadmium ratio of $0.9 \pm 0.1$ to one. For the CaS Se films, three peaks were observed and the sulfur peak decreased as the selenium concentration was increased. However, an $81 \%$ coulombic efficiency was observed, the remaining charge was attributed to secondary reactions involving oxygen and/or water, or to the reduction of sulfur contained in sulfur-oxygen species.

Roe, $\mathrm{Li}$, and Gerischer ( 30 ) have also reported the cathodic deposition of metal sulfides and selenides. The proposed reaction sequence was reported to be 


$$
\begin{aligned}
& \left.M^{n+}+n e^{-}=M_{(\operatorname{surf}}\right) \\
& X_{m}+q M_{(\operatorname{surf})}=M_{q} X_{p}(\operatorname{surf})+X_{(m-p)}
\end{aligned}
$$

or

$$
\begin{aligned}
& x_{m}+2 e^{-}=x_{m}^{2-} \\
& x_{m}^{2-}+q M^{n+}=M_{q} x_{p}(\operatorname{surf})+x_{(m-p)}
\end{aligned}
$$

Where $X_{m}$ and $X_{(m-p)}$ represent a sulfur or selenium species of unspecified molecularity.

A voltammetric study of the electrodesposition precess of CdS showed that initially, underpotential deposits of cadmium reacted with $S_{8}$ or absorbed sulfur on the electrode surface at room temperature. At $95^{\circ}$, the reaction is more complex, and direct reduction of $S_{B}$ to polysulfides competed with the electrodeposition of cas.

Hogle (34) has investigated the non-faradic reaction of $\mathrm{Cd}$ and $S$ in DMSO by UV-visible and atomic absorption spectroscopy. From his results he concluded that reaction $2 b$ yielded a soluble product having a ratio of s/Cd greater than one. $\mathrm{Cd}^{+2}$ has shown to have a capacity to react with polysulfides, and therefore, a side-reaction competes with the formation of CaS by reaction $2 \mathrm{~b}$. Cadmium metal has been shown to react with $S_{8}$ to form $\mathrm{CdS}_{p}$ and soluble polysulfide complexes. CdS p complexes have greater solubility than CdS in DMSO, and tend to stay in solution.

The purpose of this research is to obtain kinetic information about the reduction of cadmium ions, sulfur, and selenium in DMSO and their soluble products. This information in turn will be used to understand the mechanism of the reaction of formation of CdS and CdSe 
in DMSO. To achieve our goal, electrochemical measurements by linear scan voltametry, rotating ring disc electrode and high pressure liquid chromatography coupled with ultraviolet and electrochemical detectors. Experimental variables include solution temperature, concentration of reactants and electrochemical conditions.

A particularly significant experimental detail is the use of a rotating ring disc electrodes (RRDE) in this study. However, there are no RRDE commercially available which are usable at elevated temperatures. This problem was solved by developing a prototype ceramic based ring disc electrode which could be used at elevated temperatures.

The rotating ring disc electrode is almost unique for this study. The ring electrode is used to detect instantaneously soluble species produced at the disc electrode. With a RRDE, steady state is attained quickly and measurements can be made with great precision. In addition, at steady state conditions, double layer charging does not enter into measurements and the rates of mass transfer at the electrode are reproducible and known. Since the rates of mass transfer are much larger than the rates of diffusion, the relative contribution of the effect of mass transfer rates to the electron transfer kinetics can be small.

Electrochemistry of many common ions in nonaqueous solvents has appeared in the literature and has been summarized by Mann and Barnes (35). The majority of the reactions have been studied by dropping mercury electrode, and the reactions are generally diffusion controlled. In our work deposits of cadmium are achieved 
by KRDE and the kinetics of the electron transfer studied.

Studies of sulfur reduction (36) in DMSO reveal that polysulfides are formed, which is also the case in aqueous solutions (37). Spectrometric measurements by Giggenbach has shown that chain length is temperature dependant. Recent work by Streudel and Tebbe $(38,39)$ using HPLC has shown that $S_{6}, S_{7}$ and $S_{8}$ are the major species of sulfur in $\mathrm{CS}_{2}$ solutions. Our work has shown that it is also the case in DMSO. Furthermore, $S_{8}$ was reduced for the potential range studied. $S_{6}$ and $S_{7}$ are more likely absorbed on the electrode surface. RRDE studies have shown that this reduction is kinetically controlled for temperatures up to $100^{\circ} \mathrm{C}$.

Nothing is know for selenium in DMSO. Our studies followed a parallel approach to that of sulfur. We found the solubility of selenium in DMSO was increased by the addition of sulfur. Electrochemical studies by RRDE were conducted for temperatures up to $100^{\circ} \mathrm{C}$. The understanding of the electrochemical properties of $\mathrm{S}_{x} \mathrm{Se}_{\mathrm{y}}$ are significant for the possible formation of CAS-CdSe semiconductors. 
CHAPTER II

EXPER IMENTAL

\section{Reagents}

Analytical reagent grade chemicals were used unless otherwise stated. All aqueous solutions were prepared from quartz distilled water and were stored in glass flasks. Working solutions were prepared by addition of an aliquot of the stock solution by pipet or buret and/or a weighed amount of the required reagent, followed by dilution to volume by the required solvent.

Cadmium chloride. Cadmium chloride $\left(\mathrm{CdCl}_{2} \cdot 2 \frac{1}{2} \mathrm{H}_{2} \mathrm{O}\right)$ was ground to a fine powder with mortar and pestle and dried overnight at $110^{\circ} \mathrm{C}$.

Cadmium nitrate. Cadmium nitrate was used without further purification.

Dimethylsulfoxide. Dimethylsulfoxide (DMSO) technical grade from the Crown Zellerbach Company, and analytical reagent grade from the $T$. Baker Chemical Company were used without further purification. UV-risible spectra from both sources were found to be optically pure from 260 to $750 \mathrm{~nm}$. Water content was determined by the Karl Fischer titration was found to be $0.005 \%$ by weight.

Gold (III) chloride. Gold(III) chloride plating solutions were prepared by dissolving $0.3 \mathrm{~g}$ gold metal in $10 \mathrm{~mL}$ of $1: 1 \mathrm{HNO}_{3}: \mathrm{HCl}$. The acid was evaporated to almost dryness, $10 \mathrm{~mL}$ of $6 \mathrm{~F} \mathrm{HCl}$ were added and evaporated, and then diluted to $10 \mathrm{~mL}$ with quartz distilled water. 
Karl Fischer Reagent. Karl Fischer reagent and reagent diluent from the T. Baker Chemical Company were used without further purification.

Methanol. HPLC grade methanol was used without further purification.

Nitric acid. Nitric acid was used without further purification. Potassium chloride. Potassium chloride was used without further purification.

Potassium ferricyanide. Potassium ferricyanide was used without further purification.

Selenium. Pure selenium $(99.999 \%)$ was used without further purification.

Sodium borohydride. Reagent grade sodium borohydride was used without further purification.

Sodium tetrafluoroborate. Reagent grade sodium tetrafluoroborate was recrystallized from quartz distilied water.

Sulfur. Pure sulfur (99.999\%) was used without further purification.

Tetraethylammonium perchlorate. Polarografic grade tetraethylammonium perchlorate (TEAP) was used without further purification.

Water. Triply quartz distilled water was used and stored in polypropylene bottles. 


\section{Equipment}

High pressure liquid chromatograph. Water Associates liquid chromatograph, Model 6000A was used, equipped with a Model $440,254 \mathrm{~nm}$ wavelength absorbance detector, a Spectra Physics SP 8440 variable wavelength detector, a $20 \mu \mathrm{L}$ Rheodine syringe loading sample injector Model 7125 and a Beckman Ultrasphere ODS $5 \mu_{18}$ reversed phased column.

Electrochemical flow cell. A ICl7 Bioanalyical Systems electrochemical thin layer flow cell, equipped with a gold working electrode and a glassy carbon counter electrode, was connected to the outlet of the absorbance detector, in the typical three electrode arrangement to a potentiostat with current integration.

UItraviolet-visible. A Beckman Model 26 spectrophotometer with I cm quartz cuvettes was used for UV-visible spectra.

Potentiostat and rotating electrode speed control. A dual potentiostat and rotating electrode speed control was built in this laboratory. Prototype potentiostat equipped with current integrator was built by the Fritz Haber Institute in Berlin, Germany.

Rotating ring-disc electrode. A teflon insulated rotating gold ring-disc electrode (RRDE) Model TBI6 from Pine Instruments Company $\left(r_{1}=0.382 \mathrm{~cm}, r_{2}=0.399 \mathrm{~cm}, r_{3}=0.422 \mathrm{~cm}\right)$, and a prototype $\left(r_{1}=0.338\right.$ $\left.\mathrm{cm}, r_{2}=0.400 \mathrm{~cm}, r_{3}=0.600 \mathrm{~cm}\right)$ ceramic insulated, gold RRDE for high temperatures measurements were used, as shown in Figure 1.

Gold microelectrode. A gold plated platinum electrode, I mm in diameter, sealed in glass, made in this laboratory was used.

Reference and counter electrode. An aqueous $\mathrm{Ag} / \mathrm{AgCl}$ reference electrode and a $4 \mathrm{~cm}^{2}$ platinum foil was used as a counter electrode. 

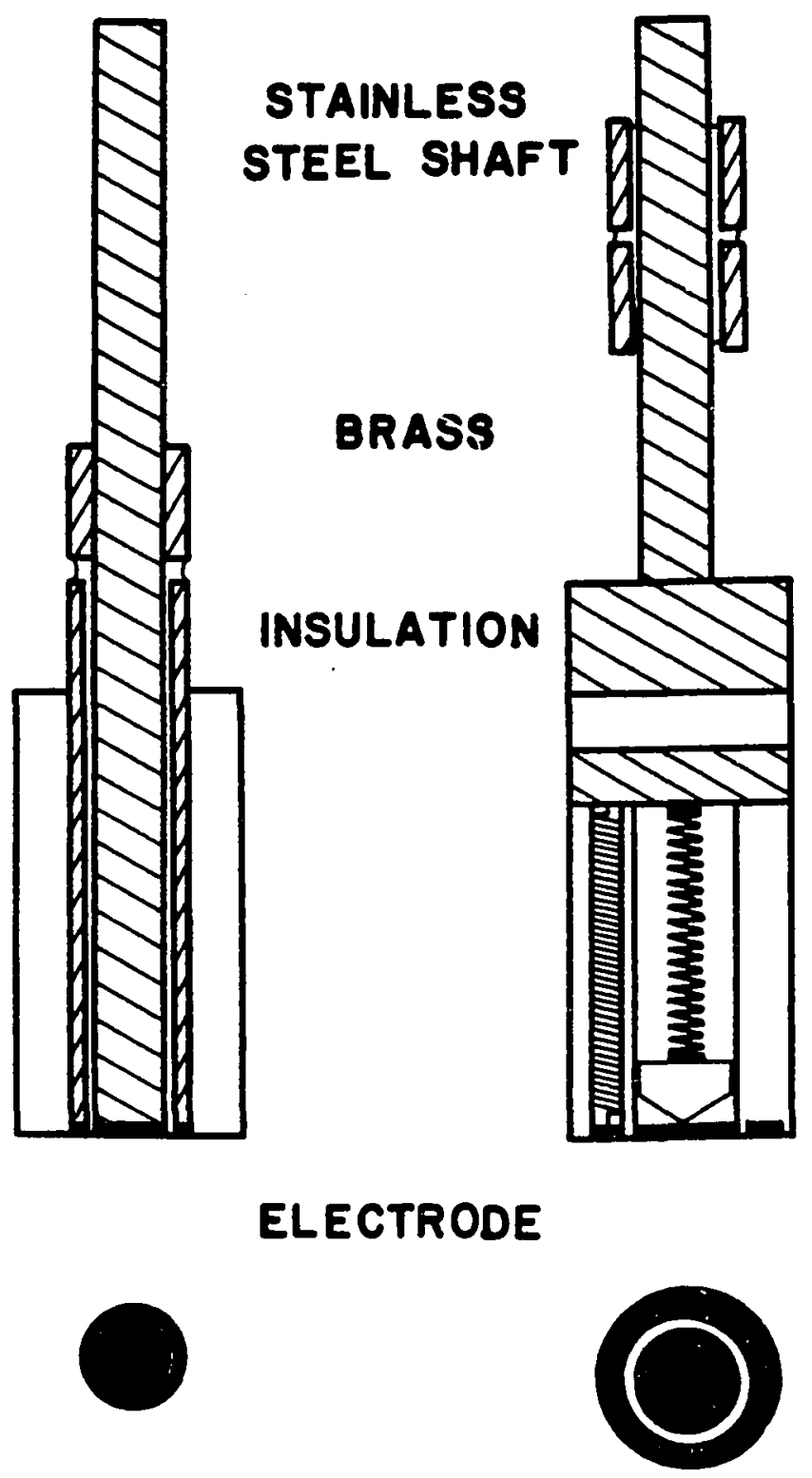

Figure 1. Rotating Ring-Disc Electrode 
CeII. GIass cells of 40 and $100 \mathrm{~mL}$, with connections for reference and counter electrodes, as well as for gas purge, were used for all measurements (See Figure 2).

Calculations. All calculations were carried out on a Hewlett Packard pocket calculator HP-25C and on a Honeywell 66/20 computer system. All data were analyzed by linear regression using the program LSQI written in Fortran by B. W. Brown. Where required, standard statistical methods were applied to the data. In such cases, the results are reported as the mean value plus and minus the standard deviation.

Experimental methods and procedures

Determination of the solubility of selenium in DMSO. The solubility of selenium in DMSO was determined as a function of temperature for the range of 23 to $140^{\circ} \mathrm{C}$. Excess selenium powder was added to 100 mI of DMSO, purged with nitrogen, heated to the desired temperature, and equilibrated for three to eight hours. Aliquots of 10 to $20 \mathrm{~mL}$ of the selenium solution were drawn, the solvent evaporated, and the selenium weighed in constant weight crucibles. Aliquots of the solvent alone were also taken as a control.

The solubility of selenium in DMSO in the presence of sulfur was determined in the same way. Sulfur was added at a known concentration below saturation. The weight of sulfur in every sample was then subtracted from the dry selenium-sulfur weights. UV spectra of the selenium, sulfur, and selenium-sulfur solutions were recorded from 240 to $360 \mathrm{~nm}$ using DMSO as a reference. Solubility of selenium in DMSO in the presence of toluene and ace- 

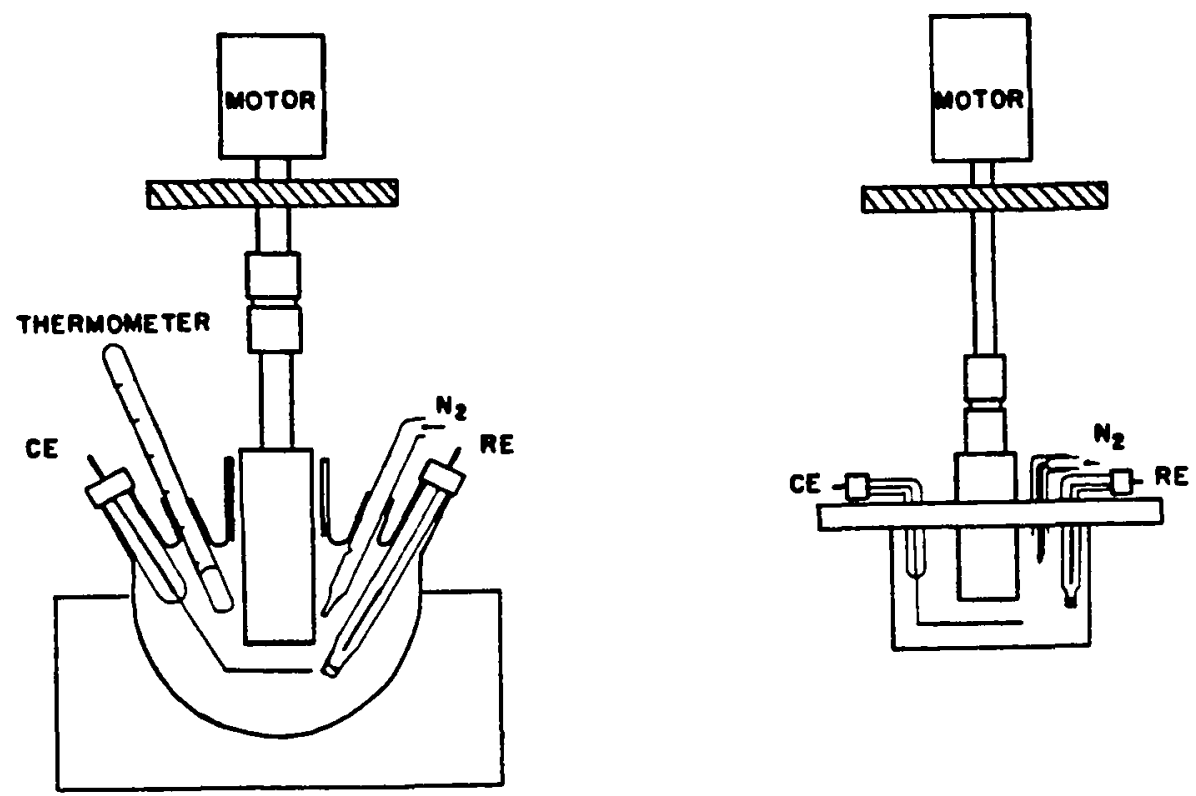

Figure 2. Electrocherical Cells for RRDE Studies. 
tonitrile, as well as selenium in sulfolane were also determined following the same method.

HPLC analysis. Samples of $20 \mu \mathrm{L}$ of sulfur and/or selenium solutions in DMSO or methanol were injected in the HPLC and eluted with methanol at $1.6 \mathrm{~mL} / \mathrm{min}$ ( $2500 \mathrm{psi}$ ), followed by $\mathrm{UV}$ detection over the range of $250-300 \mathrm{~nm}$ and by an electrochemical flow cell over the potential range of -0.35 to $-1.60 \mathrm{~V}$ versus $\mathrm{Ag} / \mathrm{AgCl}$.

Reaction of cadmium with sulfur and/or selenium. Freshly precipitated cadmium was reacted with sulfur and/or selenium in DMSO. Precipitated cadmium samples were prepared by the reduction of aqueous cadmium ion, of $1 \mathrm{M} \mathrm{Ca}\left(\mathrm{NO}_{3}\right)_{2}$, with three times the stoichiometric amount of crystalline sodium borohydride according to the reactions

$$
\begin{aligned}
& \mathrm{Cd}^{+2}+2 \mathrm{BH}_{4}^{-}=\mathrm{Cd}+\mathrm{H}_{2}+\mathrm{B}_{2} \mathrm{H}_{6} \\
& \mathrm{~B}_{2} \mathrm{H}_{6}+6 \mathrm{H}_{2} \mathrm{O}=2 \mathrm{H}_{3} \mathrm{BO}_{3}+6 \mathrm{H}_{2}
\end{aligned}
$$

Cadmium samples were collected in a glass fritted funnel, washed with distilled water, and finally washed with three $10 \mathrm{~mL}$ aliquots of DMSO. The last aliquot of DMSO was kept for a control.

Aliquots of $10 \mathrm{mI}$ of sulfur and/or selenium solution were passed through the glass fritted funnel containing the freshly precipitated cadmium. The sulfur and/or selenium solutions were analyzed before and after the reaction by HPLC.

Supporting electrolytes. Solutions of $0.1 \mathrm{~F} \mathrm{NaBF}_{4}$ were prepared by dissolving the appropriate amounts of $\mathrm{NaBF}_{4}$ in DMSO. All solutions were purged with nitrogen and electrolyzed for one hour using a platinum gauze as the working electrode at $-1.2 \mathrm{~V}$ versus $\mathrm{Ag} / \mathrm{AgCl}$. 


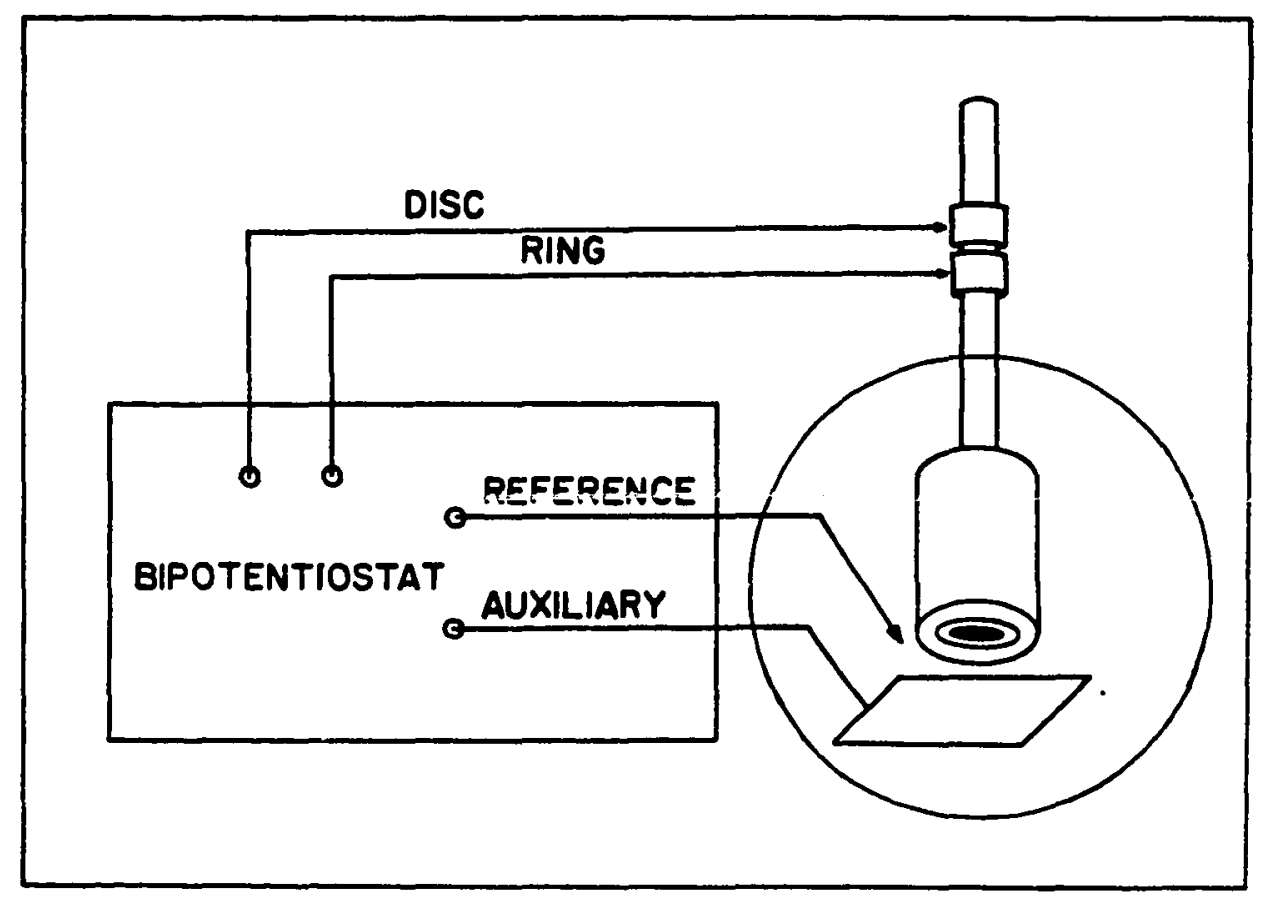

Figure 3. Dual Potentiostat for RRDE Measurements. 
Electrode pretreatment. The microelectrode and the ceramic insulated RRDE were electroplated with a $\mathrm{Au}$ (III) chloride wolution at $50^{\circ} \mathrm{C}$ and current density of $1 \mathrm{~mA} / \mathrm{cm}^{2}$, for $2-20$ minutes. The electrode was rinsed with water and polished to a mirror finish with $0.3 \mu \mathrm{m}$ alumina. The electrode was rinsed with DMSO before introduction into the cell. The microelectrode and RRDE's were preconditioned in the supporting electolyte by cyclic scanning for approximately 15 - 30 minutes and the residual current recorded at different scan rates, rotation rates, and temperatures. All of the electrochemical measurements for the microelectrode, RRDE, and flow cell were made with a dual potentiostat, or with an ordinary (three electrode) potentiostat equipped with current integrator. A schematic diagram of the electrochemical system is shown in Figure 3.

Rotating ring-disc electrode. The RRDE is constructed with a central disc surrounded by a concentric insulating annulus, followed by a concentric ring electrode as depicted in Figure 1. The electrode was developed by Frumkin and Nekrasov $(43,44)$. Because of its construction, potentials of the ring and disc can be controlled independently. Experiments can be performed which use the ring electrode to provide addilional information abcut prosesses sccurring on the disc electrode. The disc electrode can also be used as a source of species with the ring electrode as a detector of unstable species.

The equation that relates the current at the disc electrode and the rotation rate was first derived by Levich (45) in 1942. The equation predicts that the limiting current should be proportional to the square root of the rotation rate as described by equation 6 


$$
i_{D_{\text {lim }}}=1.554 \mathrm{nAFD}^{2 / 3} v^{-1 / 6} \mathrm{w}^{1 / 2} \mathrm{C}^{*}
$$

where $\mathrm{n}$ is the number of electrons, A the area of the electrode in $\mathrm{cm}^{2}$, $\sqrt{ }$ is the kinematic viscosity in $\mathrm{cm}^{2} \mathrm{~s}^{-1}, D$ is the diffusion coefficient in $\mathrm{cm}^{2} \mathrm{~s}^{-1}, \mathrm{~F}$ is the faraday constant in $\mathrm{Amp} \mathrm{s}$ mol${ }^{-1}, \mathrm{~W}$ is in hertz, and $C^{*}$ is the bulk concentration in $\operatorname{mol~} \mathrm{cm}^{-3}$.

For the ring, the mass transfer is larger than that for the disc at a given rotation rate, because the flow of fresh solution to it occurs radially from the area inside the ring as well as normally from the bulk of the solution. The equation for the limiting ring current is described by equation $7(46,47)$.

$$
i_{R_{l i m}}=1.554 \mathrm{nF} \pi\left(x_{3}^{3}-r_{2}^{3}\right)^{2 / 3} \mathrm{D}^{2 / 3} \sim^{-1 / 6} \mathrm{w}^{1 / 2} \mathrm{C}^{*} \quad 7
$$

where $r_{2}$ and $r_{3}$ are the inner and outer radii of the ring electrode in $\mathrm{cm}$.

The ring and disc currents are related by the collection efficiency $\left(N_{0}\right)$. The collection efficiency is defined as the ratio of the ring current to the disc current at a given potential $\mathrm{E}$, as shown in Figure 4 .

$$
N_{0}=-\frac{i_{R_{l i m}}}{i_{D_{l i m}}}
$$




\section{Disc}

\section{Ring}

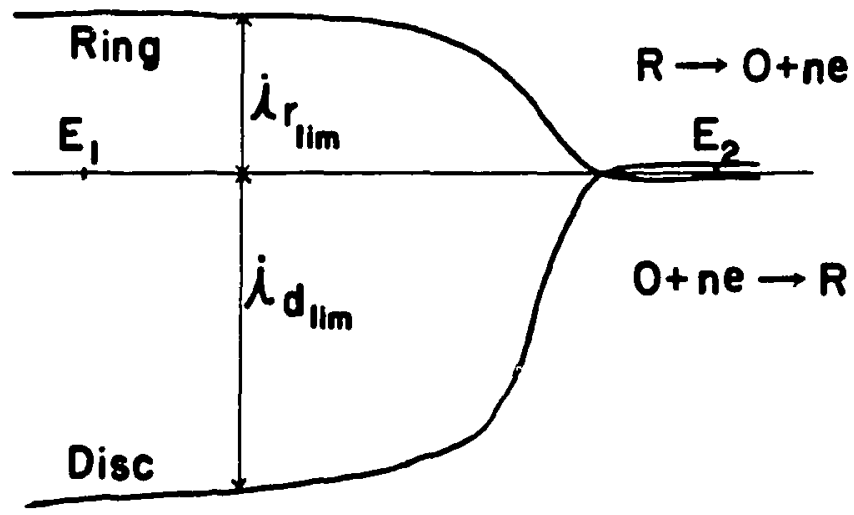

$\frac{-i_{r}}{i_{d}}=N$

Figure 4. Collection Efficiency. 
The collection efficiency is a characteristic of each electrode and may be calculated from the geometry of the electrode since it depends only on $r_{1}, r_{2}$, and $r_{3}$. The collection effeciency can also be determined experimentally for an electrode by measuring the ratio $-i_{R_{I i m}} / i_{D_{1 i m}}$ for a system

$$
0+n e^{-}=R
$$

where $R$ is more stable. $R$ is produced at the disc and is reoxidized at the ring. The collection efficiency is independent of the rotation rate.

Collection efficiency for the RRDE. The collection efficiency for the RRDE's was determined experimentally using $\mathrm{Fe}(\mathrm{CN})_{0}^{-3} / \mathrm{Fe}(\mathrm{CN})_{6}^{-4}$ in $0.1 \mathrm{~F} \mathrm{H}_{2} \mathrm{SO}_{4}$. The RRDE was rotated at 500. 1000. 2000, 3000, and 5000 rpm and scanned from +0.3 to $-0.8 \mathrm{~V}$ versus $\mathrm{Ag} / \mathrm{AgCl}$ at $20 \mathrm{mV} / \mathrm{s}$. The $\mathrm{ring}$ and disc currents were measured at $E_{D}=-0.5 \mathrm{~V}$ while the ring was kept at $+0.1 \mathrm{~V}$. The collection efficiency was determined to be 0.547 for the teflon electrode and 0.493 for the ceramic electrode. The results agreed within $1 \%$ of the theoretical values calculated from the equations given by Albery and Hitchman (46).

Reaction at the RRDE. The rotating disc electrode was scanned for potentials where reaction 9 occurs. Disc currents measurements were made at the plateau of the limiting currents for the different rotation rates, and corrected for the residual currents at the given potential. Intermediate products were searched for by scanning the ring at potentials $\left(E_{R}\right)$ where reaction

$$
R-n e^{-}=C
$$


occurs, and where $C$ may or may not be equal to $O$, while the disc potential was set to produce $R$. From the ring scans, a ring potential ( $F_{R}$ ) was selected to follow the reoxidation of the soluble product(s) for the different rotation rates.

Kinetic currents and diffusion coefficients. For reversible reactions $i$ varies as $w^{\frac{1}{2}}$ at any potential. A deviation of a plot versus $w^{\frac{1}{2}}$ from a straight line that intersects the origin suggests some kinetic step involved in the electron transfer reaction. Should the reaction be completely irreversible a kinetic current $\left(i_{k}\right)$ can be defined as

$$
i_{k}=n F A k_{f}(E) C^{*}
$$

Therefore, the total observed current $(i)$ at the disc for an irreversible reaction can be expressed as

$$
\frac{1}{i}=\frac{1}{i_{k}}+\frac{1}{i_{L}}=\frac{1}{i_{k}}+\frac{1}{1.554 \mathrm{nFAC} D^{2 / 3} \sqrt{ }^{-1 / 6} \mathrm{w}^{\frac{1}{2}}}
$$

It is clear from equation 12 , that $i / w^{\frac{1}{2}} \mathrm{C}$ is constant when $i_{k}$ is very large. When this is not the case the plot of $i$ versus $w^{\frac{1}{2}}$ will be bent toward the limit $i=i_{k}$ as $w^{\frac{1}{2}}$ goes to infinity. A plot of $l / i$ versus $l / w^{\frac{1}{2}}$ should be linear and can be extrapolated to $w^{-\frac{1}{2}}=0$ to obtain $i_{k}^{-1}(58)$.

From plots $(i / A C)^{-1}$ versus $w^{-\frac{1}{2}}$ the kinetic currents were determined and with equation 11 the heterogeneous rate constants for the forward reaction in the reduction of sulfur, selenium and cadmium ion were calculated. From the slopes of these graphs and equation 6 , the diffusion coefficients were calculated. 


\section{CHAPTER III}

RESULTS

\section{Selenium}

Solubility of selenium. The solubility of selenium in DMSO follows an exponential growth with temperature for the range of $20^{\circ}$ to $140^{\circ} \mathrm{C}$, as shown in Figure 5 . The solubility can be expressed in terms of the following expression, where the concentration of selenium is expressed in $\mathrm{mM}$ (as $\mathrm{Se}$ ).

$$
\log \mathrm{Se}=-1000.9 \frac{\mathrm{l}}{\mathrm{T}}+2.93
$$

From the UV spectrum for selenium in DMSO the absorbance was measured at $261 \mathrm{~nm}$. The molar absorptivity $(\varepsilon)$ was found to be $(11.47 \pm 0.01) \times 10^{2} \mathrm{~L}$ mole $\mathrm{em}^{-1}$ by measuring a range of standards $\left(4.3 \times 10^{-5}\right.$ to $\left.1.9 \times 10^{-4} \mathrm{M}\right)$. Beer's law was obeyed over the concentration range studied. The additions of small amounts of sulfur enhances the selenium solubility, for the range of temperatures $50-100^{\circ} \mathrm{C}$ as shown in Figure 6. Addition of more than $0.25 \mathrm{mM}$ of sulfur does not continue to enhance selenium solubility. (See Figure 6.) The UV spectra for sulfur-selenium solutions do not show appreciable changes compared to the spectrum of selenium. For sulfur concentrations larger than $0.25 \mathrm{mF}$, the UV spectrum for sulfurselenium starts to resemble the sulfur spectrum. 


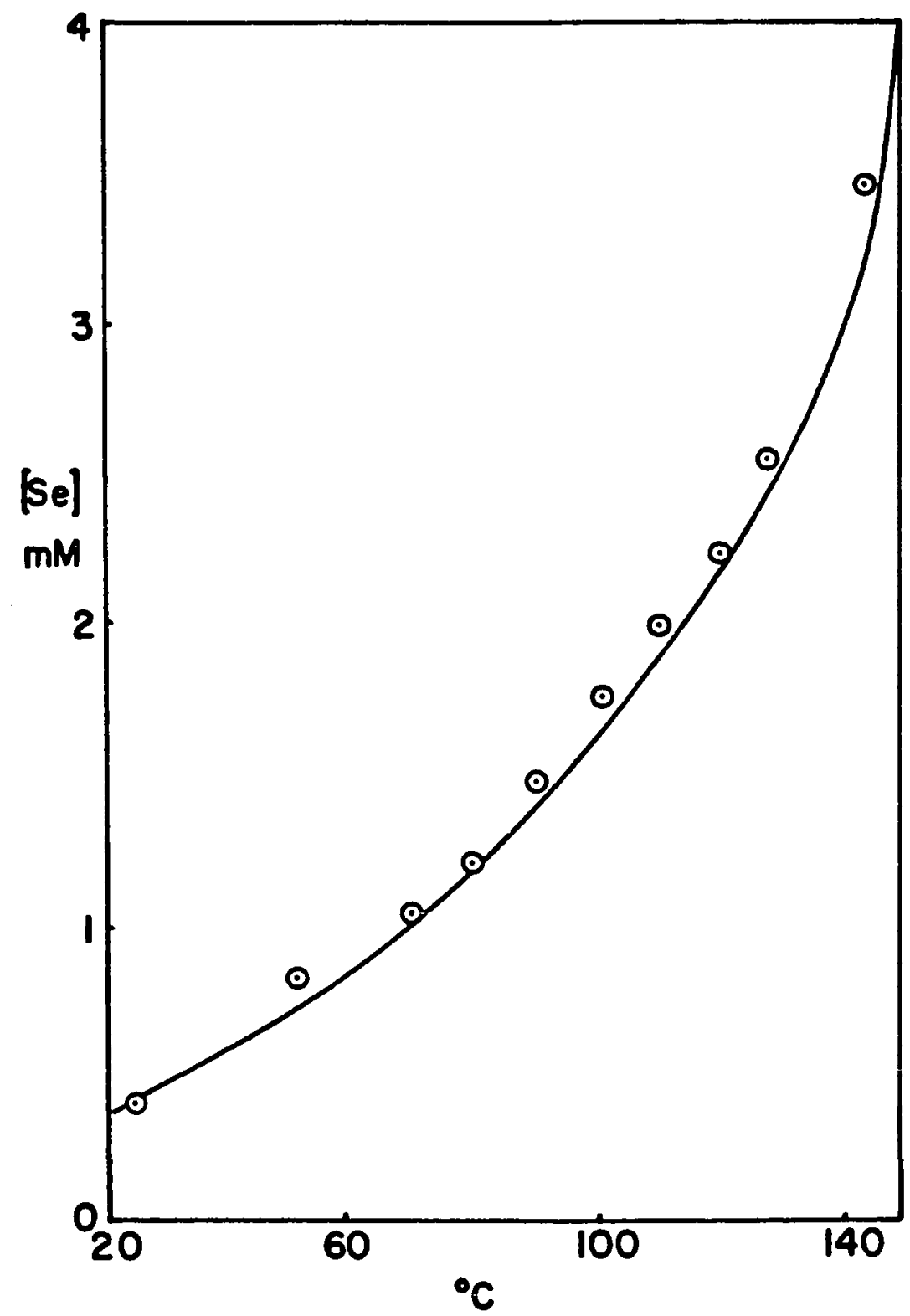

Figure 5. Solubility of Selenium as a Function of Temperature. 


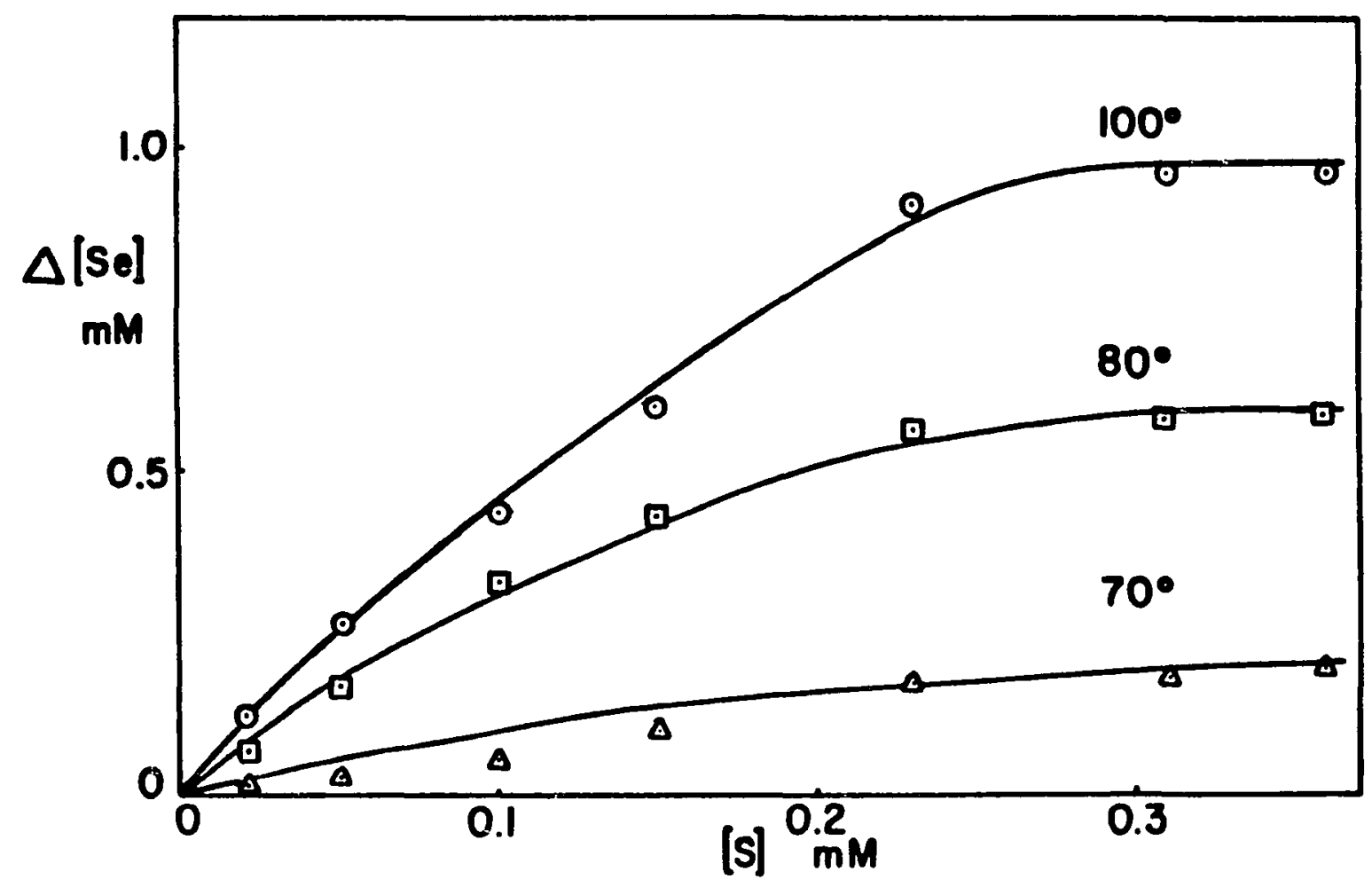

Figure 6. Tncrease of Selenium Solubility in DMSO in the Presence of sulfur. 
Electrochemistry of selenium. The electrochemistry of selenium was studied over the potential range of 0.4 to $-1.6 \mathrm{v}$ versus $\mathrm{Ag} / \mathrm{AgCl}$. The reduction of selenium starts at $-1.2 \mathrm{~V}$ reaching a diffusion plateau at $-1.4 \mathrm{~V}$. A typical scan is shown in Figure 7.

The concentrations studied were under the saturation concentration at room temperature ( $\mathrm{Se}_{8}=4.25 \times 10^{-5} \mathrm{~F}$ ). At concentrations Ereater than this value, a film of elemental selenium precipitates on the surface of the electrode, preventing further reduction.

The disc currents show some curvature on plots of $i_{L}$ versus $w^{\frac{1}{2}}$, particularly for high values of $\mathrm{w}^{\frac{1}{2}}$, as shown in Figure 8 , for concentrations under $4.25 \times 10^{-5}$. The observed ring currents agreed with those predicted from the collection efficiency $\left(\mathbb{N}_{0}\right)$. The kinetic current was determined from the plots of $\left(i_{L} / A C\right)^{-1}$ versus $\mathrm{w}^{-\frac{1}{2}}$, as shown in Figure 9.

The diffusion coefficient for selenium was calculated from the slopes of $\mathrm{AC} / i_{L}$ versus $\mathrm{w}^{-\frac{1}{2}}$ and equation 1 , using the values of the kinematic viscosity from viscosity and density data given by Janz and Tomkins (54). The average value of $D$ was $(5.51 \pm 0.63) \times 10^{-5}$ $\mathrm{cm}^{2} / 5$

Table I presents the heterogeneous rate constant $k^{\circ}$ for the reduction of selenium at room temperature. 


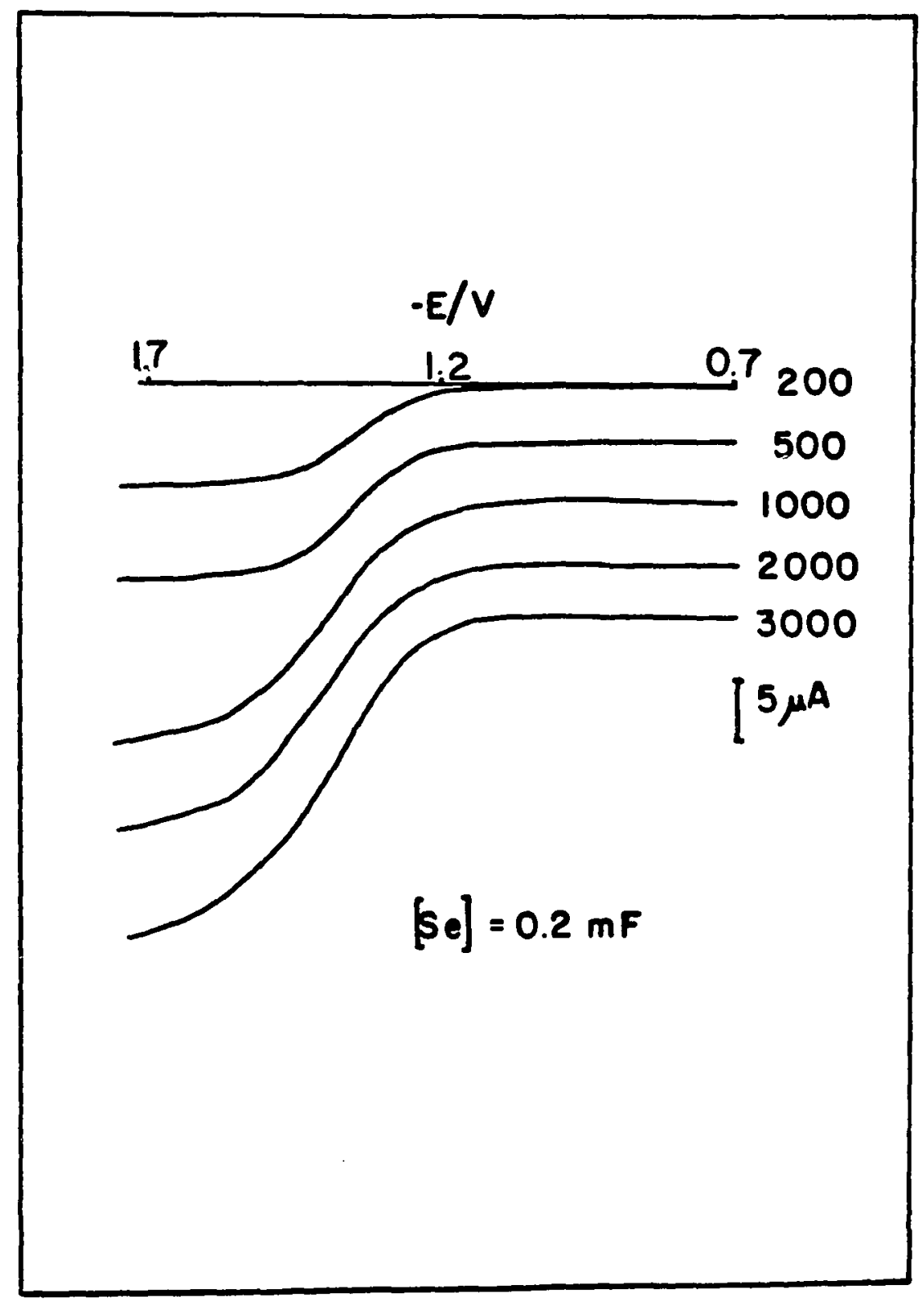

Figure 7. Reduction of Selenium at a Rotating Ring Disc Electrode at $23^{\circ} \mathrm{C}$ 


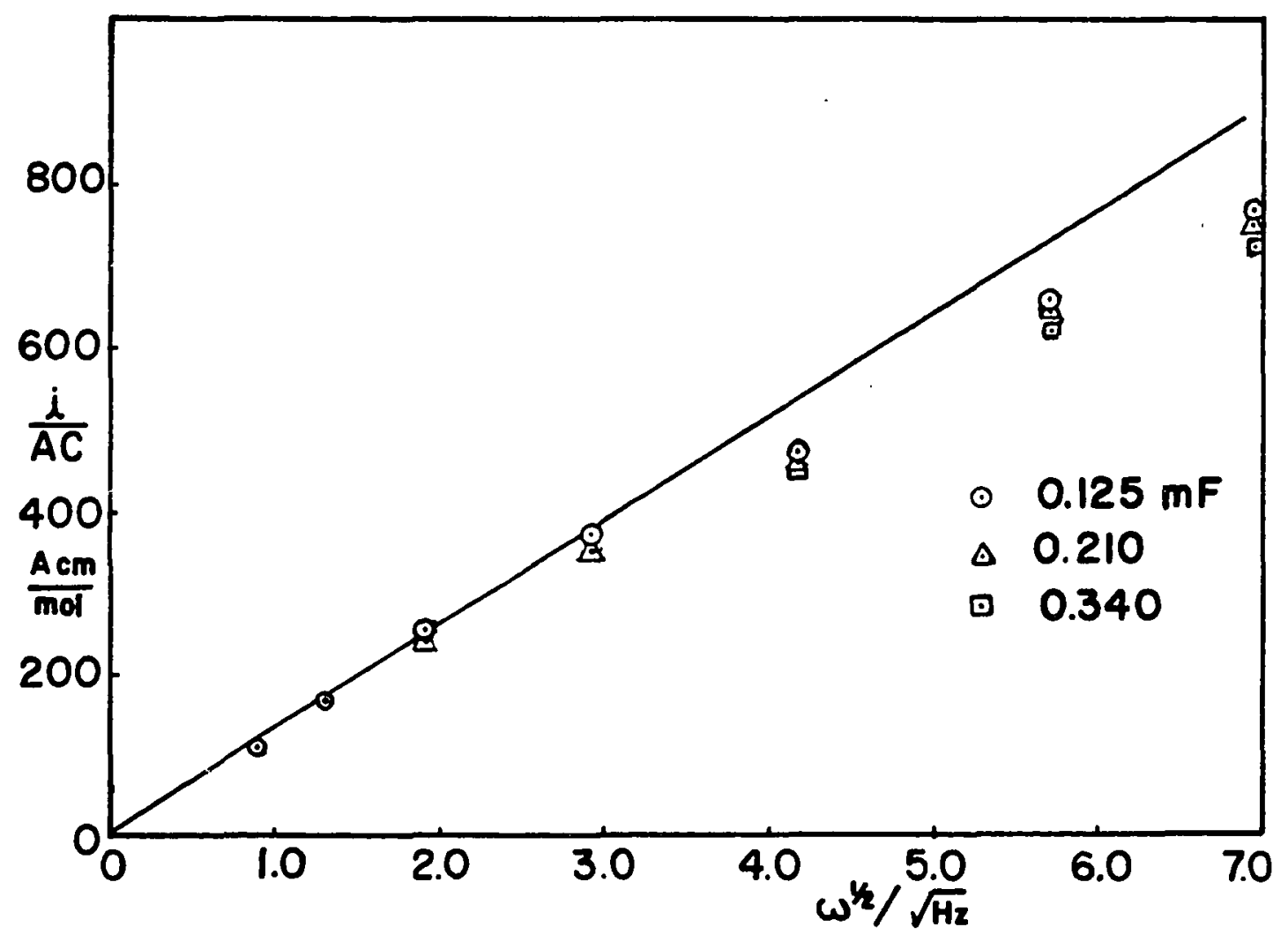

Figure 8. Effect of $w^{\frac{1}{2}}$ on Disc Currents for Selenium at $-1.4 \mathrm{~V}$ at $23^{\circ} \mathrm{C}$. 


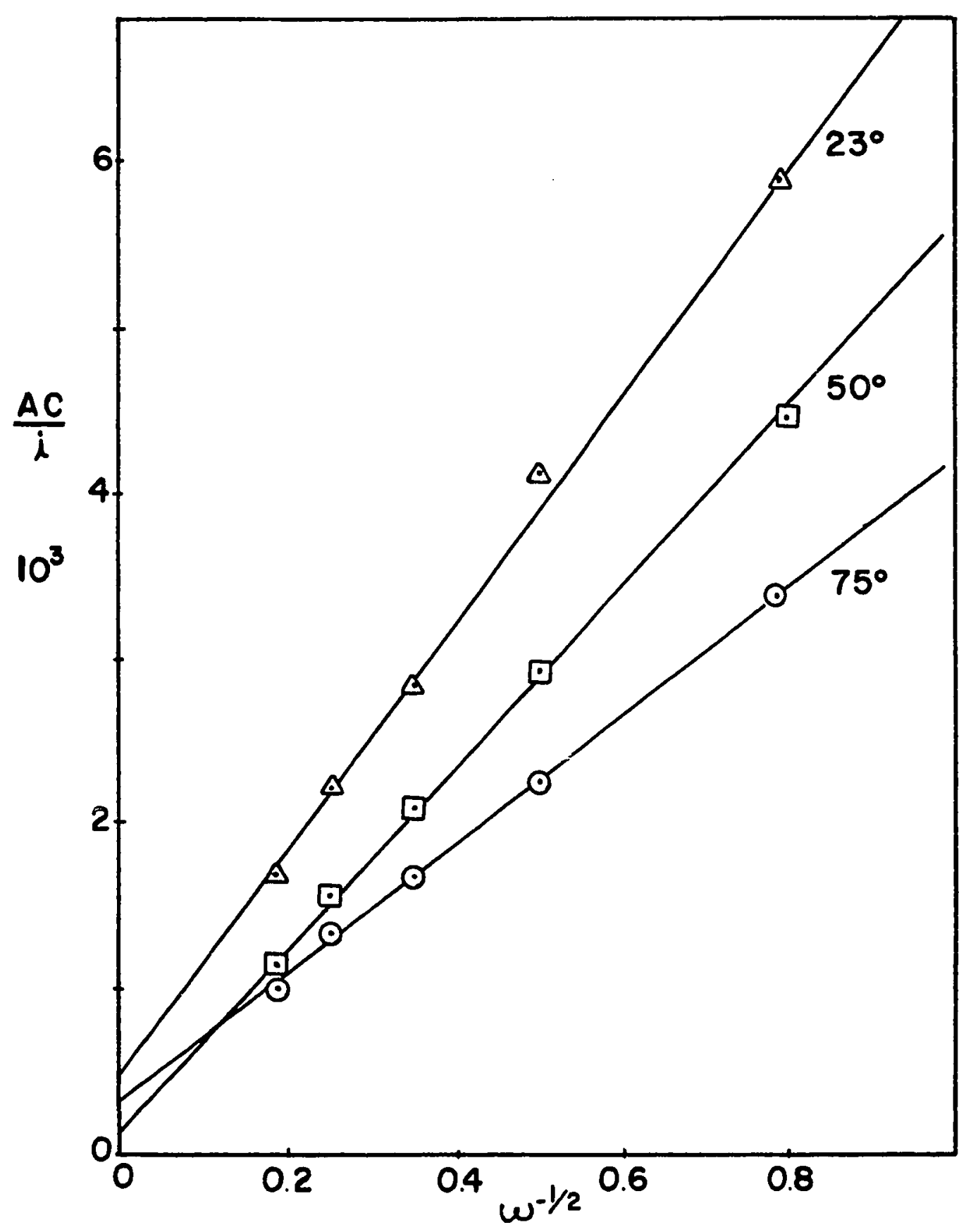

Figure 9. Temperature Effect on Disc Currents for Selenium. 
TABLE I

RATE CONSTANTS FOR THE REDUCTION OF SELENIUM

\begin{tabular}{ccc}
$\mathrm{Se}_{8} \times 10^{5}$ & $\mathrm{i}_{\mathrm{k}} / \mathrm{AC} \times 10^{3}$ & $\mathrm{k}^{0} \mathrm{~cm} \cdot \mathrm{s}^{-1}$ \\
\hline 4.25 & 3.19 & $1.58 \times 10^{-5}$ \\
2.63 & 3.07 & $7.94 \times 10^{-5}$ \\
1.46 & 2.53 & $5.02 \times 10^{-6}$ \\
\hline
\end{tabular}

The transfer coefficient $(\alpha)$ was calculated from the slope of plots of the $-\log \mathrm{k}$ versus $-\log \mathrm{C}$. for the different potentials as shown in Figure 10. The average value was found to be $0.52 \pm 0.04$. HPLC separation. Selenium in DMSO was separated by HPLC into $\mathrm{Se}_{6}, \mathrm{Se}_{7}$, and $\mathrm{Se}_{8}$ fractions. A typical chromatogram for the selenium fractions is given in Figure 11 . The retention times and capacity factors $\left(k^{\prime}\right)$ for each species are given in Table II.

TABLE II

HPLC SEPARATION OF SELENIUM

\begin{tabular}{cccc} 
Species & $\mathrm{R}_{\mathrm{t}}(\min )$ & $\mathrm{k}^{\prime}$ & $\log \mathrm{k}^{\prime}$ \\
\hline $\mathrm{Se}_{6}$ & 2.24 & 1.40 & 0.15 \\
$\mathrm{Se}_{7}$ & 3.04 & 1.90 & 0.28 \\
$\mathrm{Se}_{8}$ & 5.52 & 3.45 & 0.54 \\
\hline
\end{tabular}




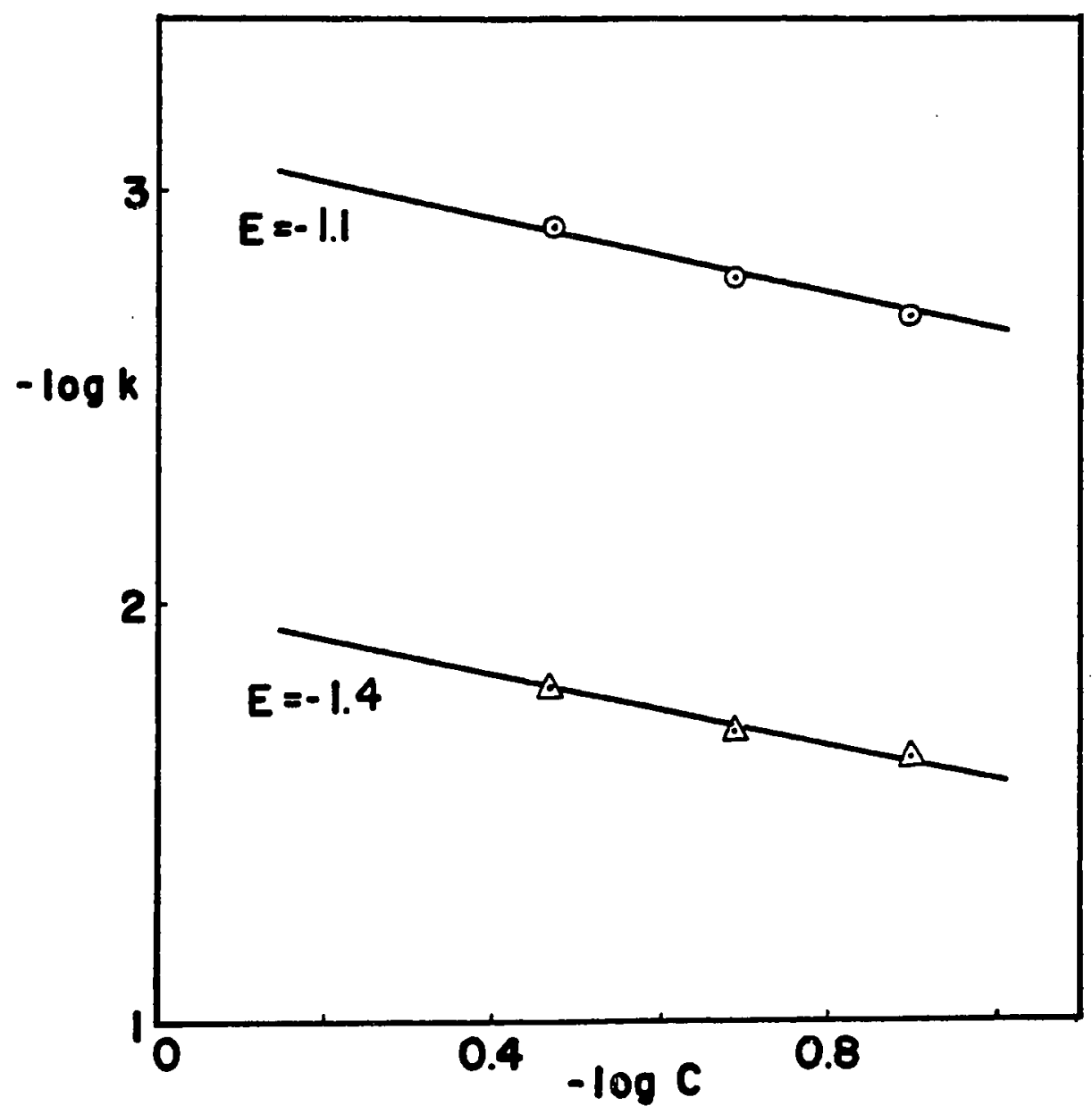

Figure 10. -Log k Vs -Log C for Selenium. 


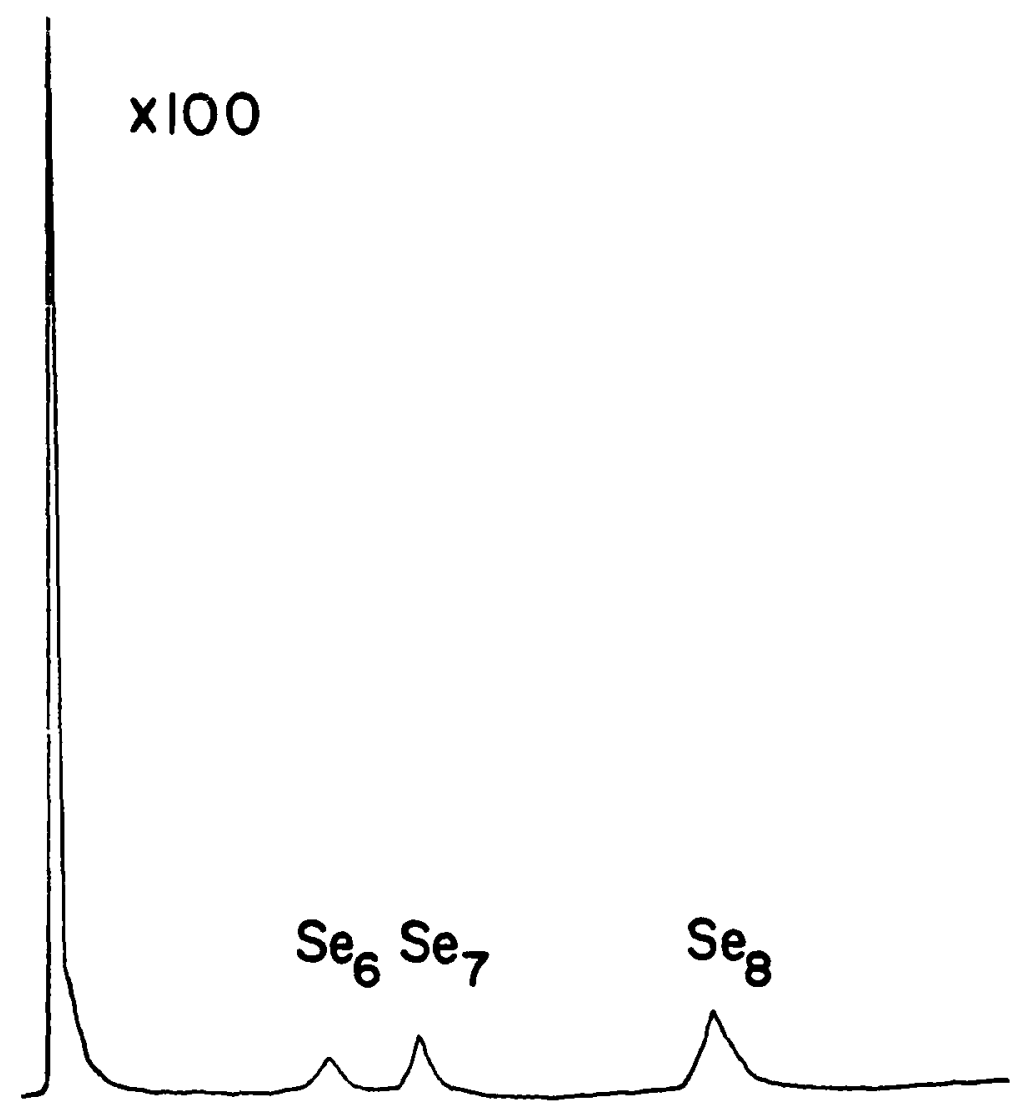

Figure 11. HPLC Separation of Selenium in DMSO. 
Reaction between metallic cadmium and selenium. The reaction was followed by HPLC, a typical chromatograph for this reaction is given in Figure 12. Table III shows the relative amounts of selenium before and after the reaction with cadmium.

TABIE III

REACTION OF $\mathrm{Se}_{\mathbf{x}}$ WITH METALLIC CADMIUM

\begin{tabular}{ccccc}
\hline $\begin{array}{c}\text { Total } \\
\text { Cadmium } \\
\text { mg. }\end{array}$ & $\mathrm{Se}_{\mathrm{x}}$ & $\begin{array}{c}\text { Before } \\
\text { Reaction }\end{array}$ & $\begin{array}{c}\text { After } \\
\text { Reaction }\end{array}$ & $\begin{array}{c}\% \\
\text { Change }\end{array}$ \\
30 & $\mathrm{Se}_{6}$ & $3.5 \times 10^{-4}$ & $1.7 \times 10^{-4}$ & 51 \\
& $\mathrm{Se}_{7}$ & $5.2 \times 10^{-4}$ & $2.2 \times 10^{-4}$ & 58 \\
& $\mathrm{Se}_{8}$ & $7.8 \times 10^{-4}$ & $4.2 \times 10^{-4}$ & 46 \\
50 & $\mathrm{Se}_{6}$ & $3.5 \times 10^{-4}$ & $1.3 \times 10^{-4}$ & 63 \\
& $\mathrm{Se}_{7}$ & $5.2 \times 10^{-4}$ & $1.7 \times 10^{-4}$ & 67 \\
& $\mathrm{Se}_{8}$ & $7.8 \times 10^{-4}$ & $3.0 \times 10^{-4}$ & 62 \\
& $\mathrm{Se}_{6}$ & $3.5 \times 10^{-4}$ & 0 & 100 \\
& $\mathrm{Se}_{7}$ & $5.2 \times 10^{-4}$ & 0 & 100 \\
& $\mathrm{Se}_{8}$ & $7.8 \times 10^{-4}$ & $1.7 \times 10^{-5}$ & 98 \\
\hline
\end{tabular}




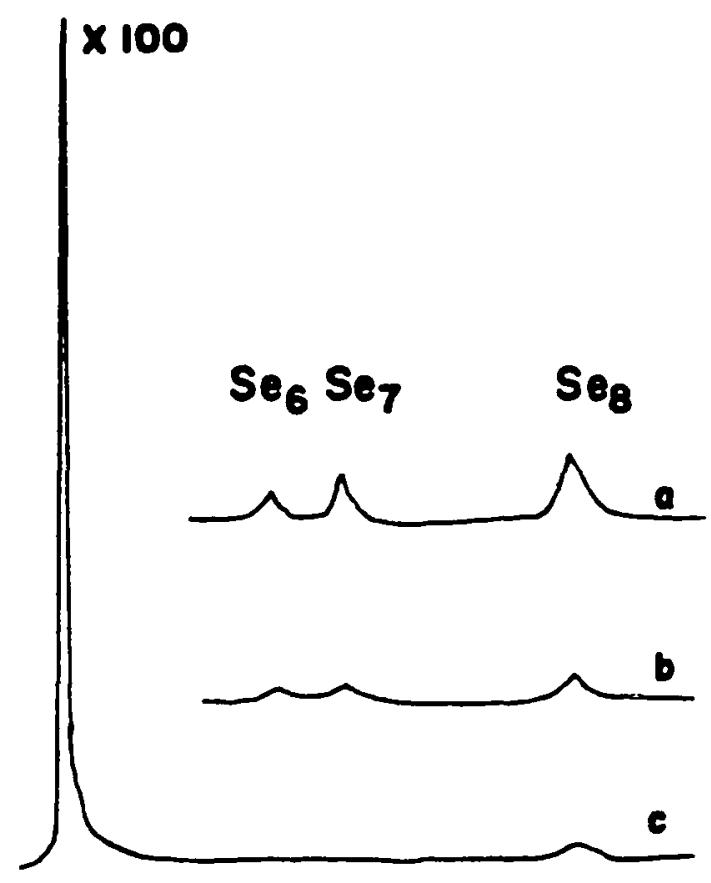

Figure 12. HPLC Chromatograms of a Saturated Selenium Solution a) Before Reaction b), c) After Reaction with 50 and $100 \mathrm{mg}$ of Metallic Cadmium. 
Sulfur

Electrochemistry. Current voltage curves for the reduction of sulfur over the potential range of 0.0 to $-1.0 \mathrm{~V}$ versus $\mathrm{Ag} / \mathrm{AgCl}$, at rotation rates of 200 to $4000 \mathrm{rpm}$, concentration range of 0.10 to $0.75 \mathrm{mF}$ and temperatures of 23 to $100^{\circ} \mathrm{C}$ were recorded. A typical run for a given concentration and at room temperature for the disc is given in Figure 13.

Results covering the concentration range are summarized in Figure 14 for the normalized current at $-0.8 \mathrm{~V}$. All of these plots have curvature, increasing at very high rotation rates. Separation of diffusion and kinetic contribution to the total current are shown by reciprocal lpots in Figure 15 for several potentials and in Figure 16 for several temperatures.

The diffusion coefficient (D) for $S_{8}$ in DMSO was calculated from the slope of the plots of Figure 16 according to equation 1 . The diffusion coefficient follows expression 14 for the range of temperatures $23-100^{\circ} \mathrm{C}$, where $\mathrm{T}$ is in kelvin.

$$
\log D=-910.75\left(\frac{1}{T}\right)-2.31
$$

At $25^{\circ} \mathrm{C}$ D was equal to $1.95 \times 10^{-6} \mathrm{~cm}^{2} \mathrm{~s}^{-1}$

Kinetic currents were also determined from Figures 15 and 16. The plot was fitted by a least squares method and extrapolated to $w^{-\frac{1}{2}}=0$. A summary of the kinetic current values is given in Table IV. 
TABLE IV

INTERCEPT VALUES OF ( $\left.\frac{A C}{i}\right)$ FOR SULFUR REDUCTION $\times 10^{3}$

\begin{tabular}{cccc}
$\mathrm{mF}$ & $23^{\circ}$ & $50^{\circ}$ & $75^{\circ}$ \\
\hline 0.10 & $0.299 \pm 0.089$ & $0.278 \pm 0.048$ & $0.220 \pm 0.021$ \\
0.20 & $0.375 \pm 0.102$ & $0.229 \pm 0.031$ & $0.186 \pm 0.031$ \\
0.40 & $0.420 \pm 0.089$ & $0.278 \pm 0.039$ & $0.200 \pm 0.017$ \\
0.75 & $0.414 \pm 0.061$ & $0.285 \pm 0.055$ & $0.202 \pm 0.032$ \\
\hline
\end{tabular}

The reaction rate constant was calculated from $i_{k}$ and equation 11. Average rate constants are given in Table V. The transfer coefficient $(\alpha)$ was calculated from a plot of $-\log k$ versus $-\log C$ for the different potentials as shown in Figure 17. Rate constants at $-0.8 \mathrm{~V}$ at several temperatures are summarized in Table V.

TABLE V

HETEROGENEOUS RATE CONSTANTS FOR THE REDUCTION OF SULFUR

\begin{tabular}{lc}
${ }^{\circ} \mathrm{C}$ & $\mathrm{k}^{\circ} \mathrm{cm} \cdot \mathrm{s}^{-1}$ \\
\hline 25 & $3.31 \pm 0.04 \times 10^{-4}$ \\
50 & $5.47 \pm 0.11 \times 10^{-4}$ \\
75 & $7.32 \pm 0.12 \times 10^{-4}$ \\
\hline
\end{tabular}




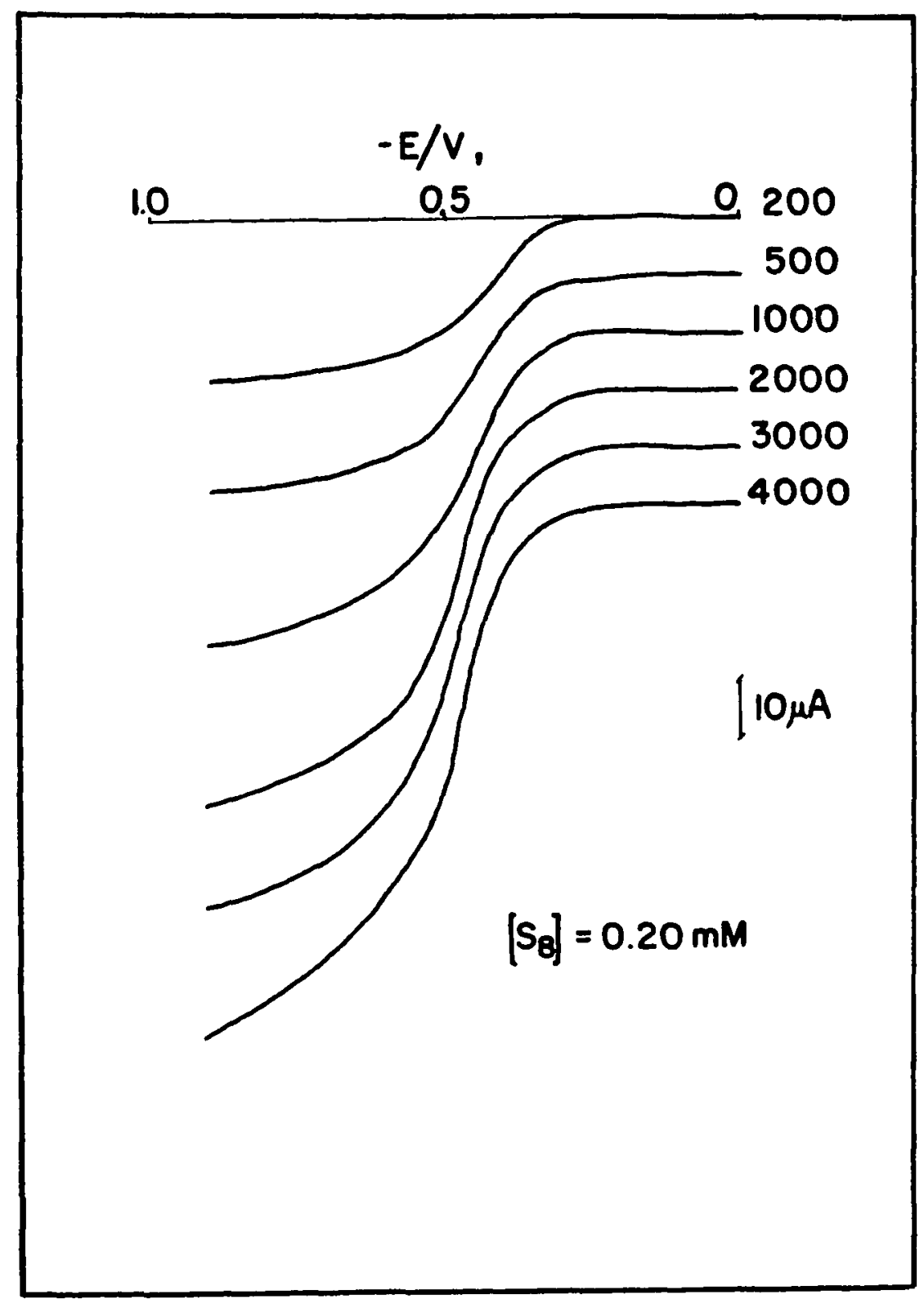

Figure 13. Reduction of Sulfur at a Rotating Ring-Disc Electrode. 


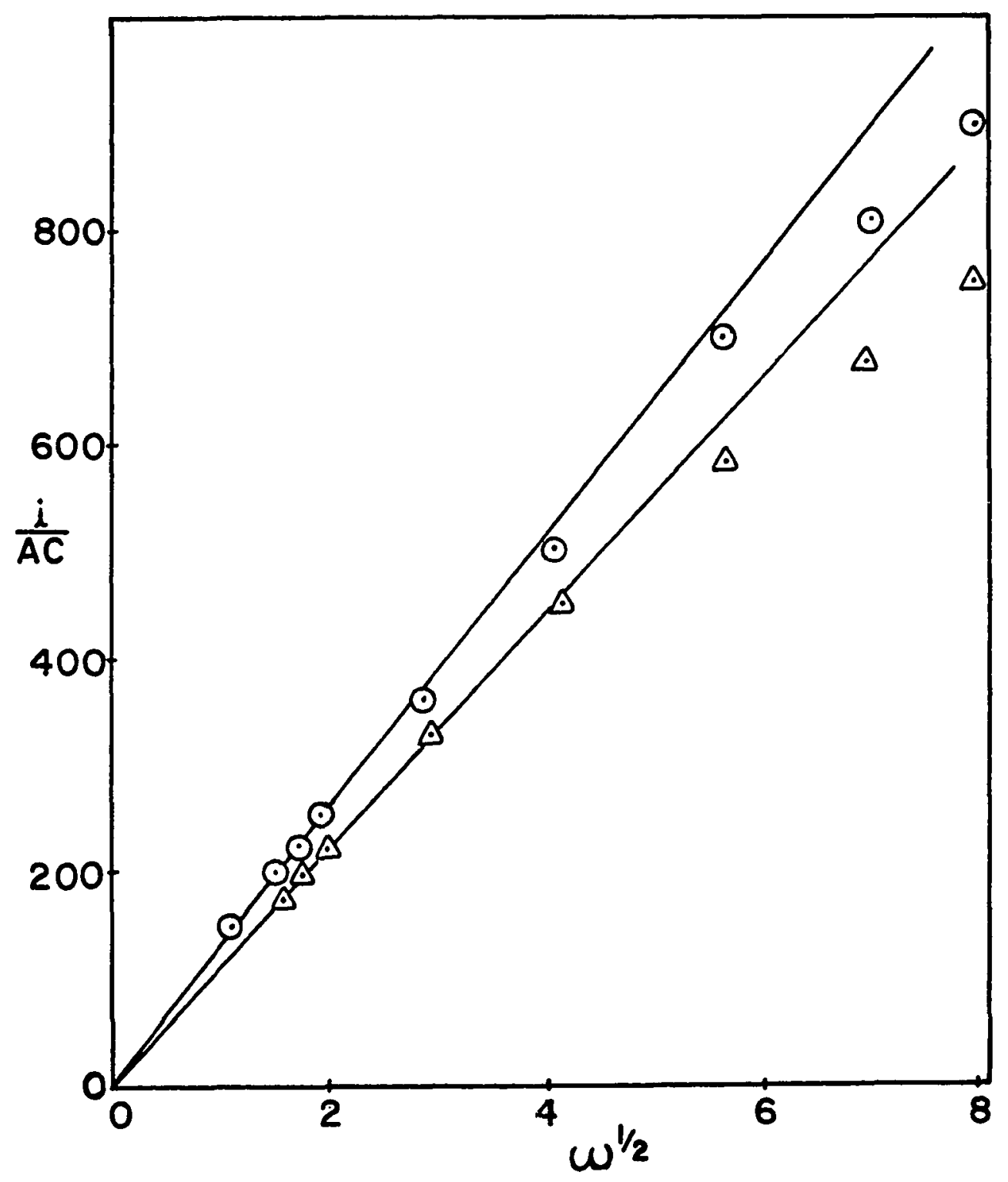

Figure 14. Effect of $w^{\frac{1}{2}}$ on Disc Current $i_{D}$ for $S_{8}$ at $23^{\circ} \mathrm{C}$. 


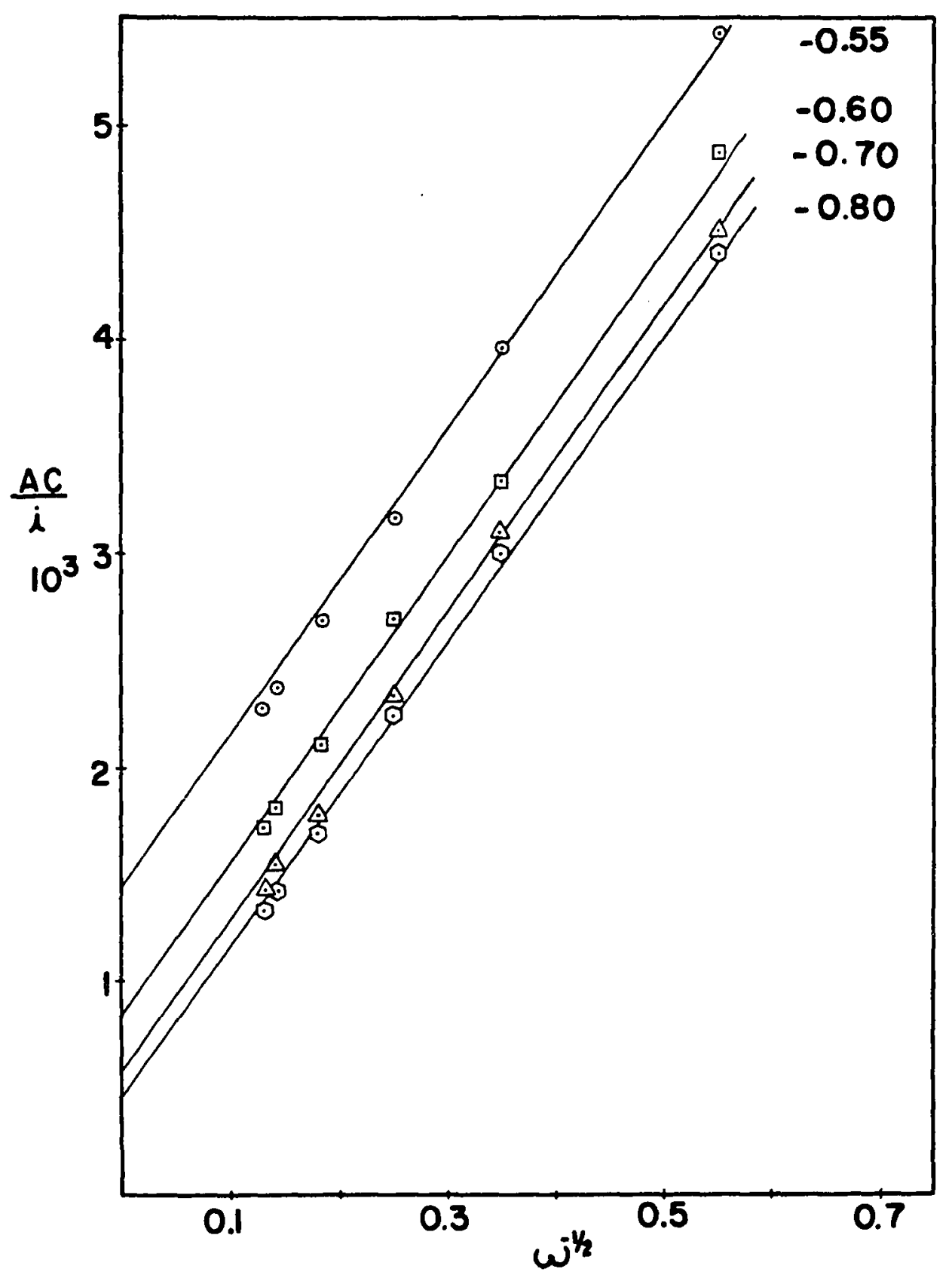

Figure 15. Effect of the Disc Potentials on the Kinetic Currents 


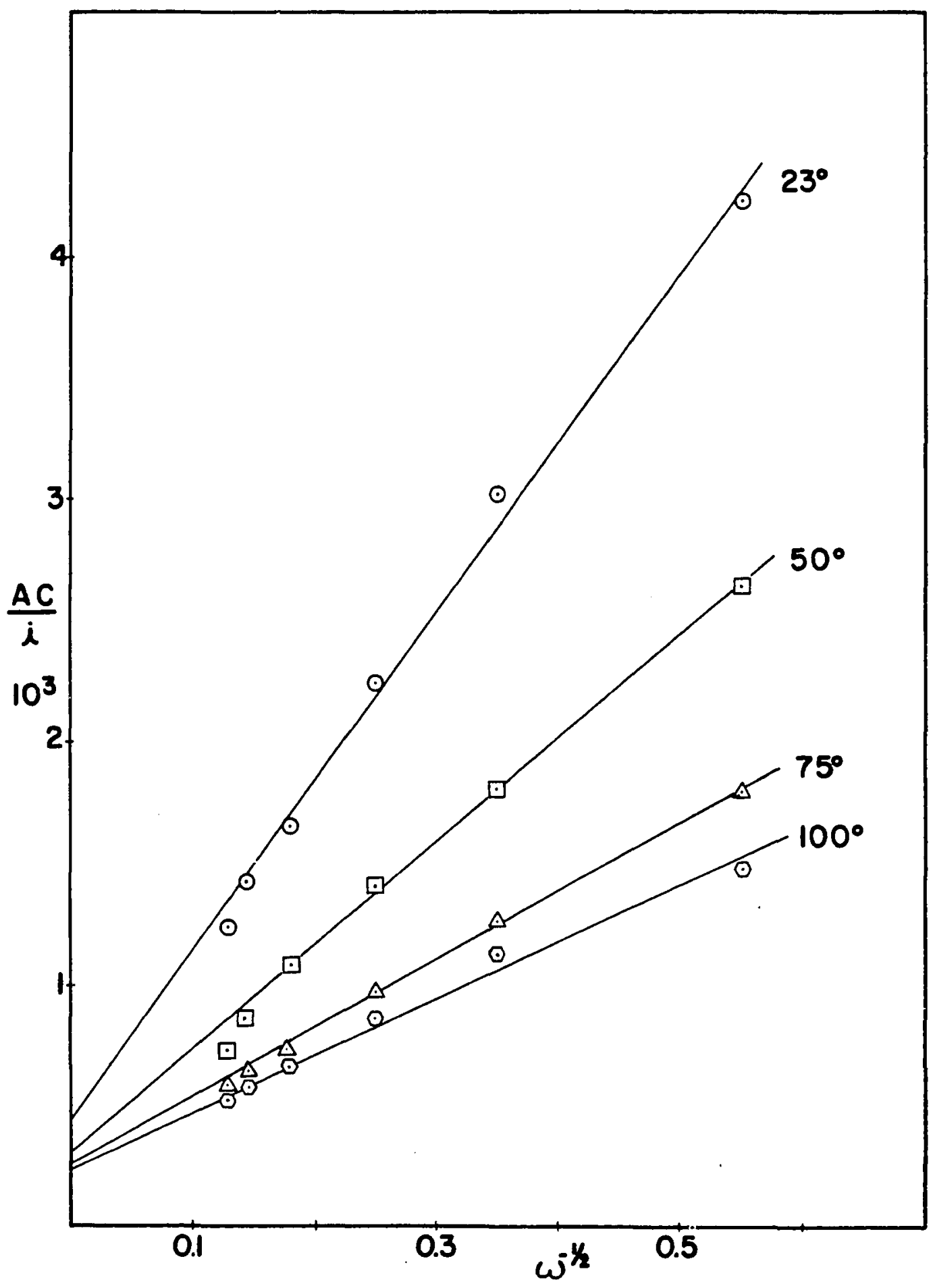

Figure 16. Temperature Effect on $(1 / A C)^{-1}$ for $S_{8}$. 
Ring measurements of products during the reduction of sulfur. The ring electrode was scanned in search of products from to. 7 to $-1.0 \mathrm{~V}$ while the disc electrode was kept at $-0.8 \mathrm{~V}$ during the reduction of $\mathrm{S}_{8}$ to $\mathrm{S}_{8}{ }^{-2}$. A typical scan is shown in Figure 18. At $23^{\circ}$ ring current measured at $+0.4 \mathrm{~V}$ versus $\mathrm{Ag} / \mathrm{AgCl}$ agree with those calculated from the collection efficiency (see Figure 19).

As the temperature was increased the solution changed color from clear to a light blue-green and the ring electrode scans did not show as steep a rise and ring currents were approximately 50\% lower than those predicted from the collection efficiency (Figure 18). An apparent reaction between the produced polysulfides and oxygen was suspected since ring currents decreased with time. A new set of experiments in a glove bag filled with nitrogen were conducted to test this possibility. Disc-ring currents improved only by $\sim 3 \%$, indicating that oxygen was not responsible for the decrease in currents, but instead a slow reaction with the gold electrode may be occurring since a brown film was found on the electrode surface.

HPLC separation. Sulfur in DMSO solutions were separated into fractions of $S_{6}, S_{7}$, and $S_{8}$. A typical chromatogram of this separation is shown in Figure 20. The retention times $\left(R_{t}\right)$ and capacity factors $\left(k^{\prime}\right)$ are given in Table VI. 


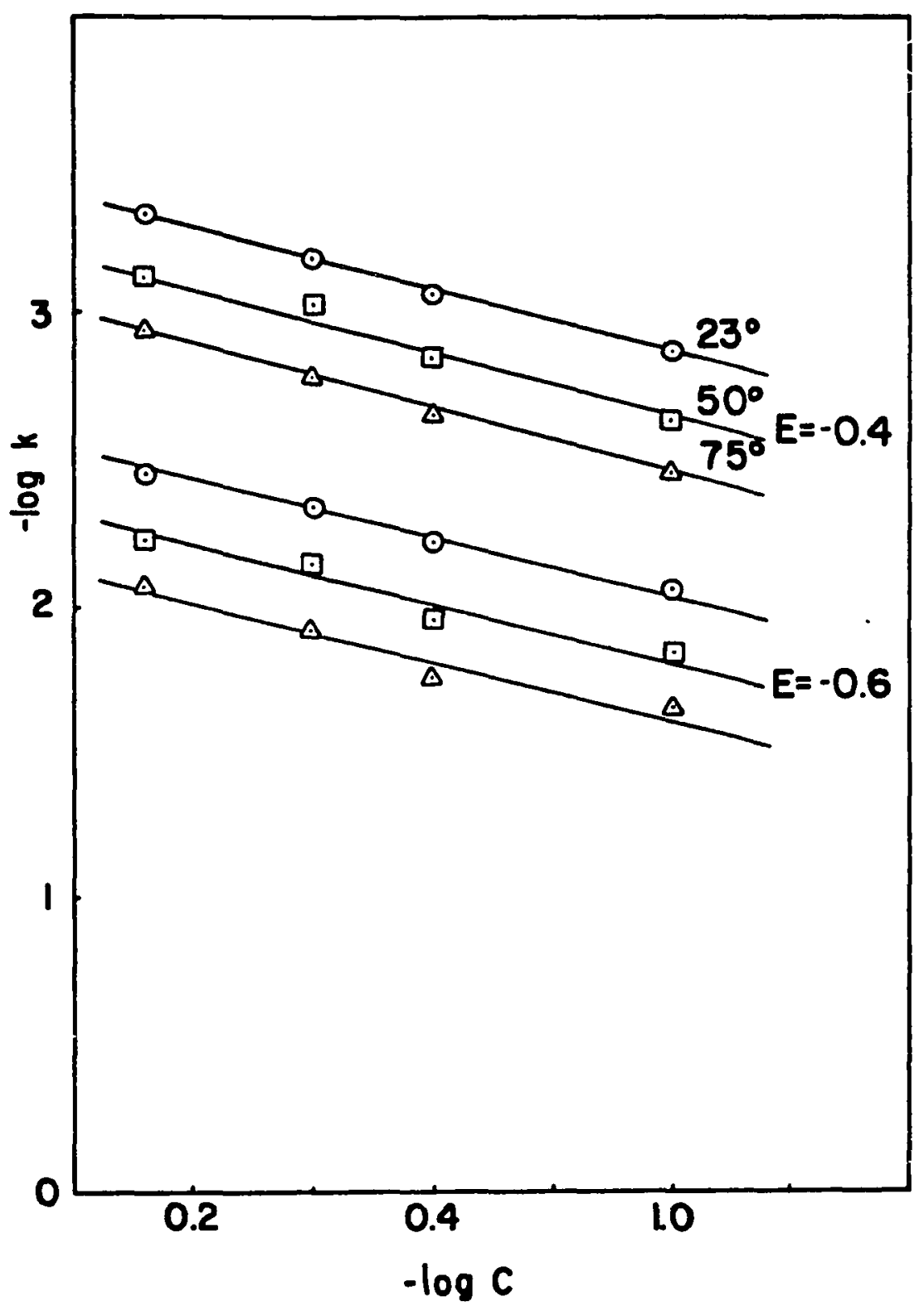

Figure 17. - Log $k$ versus - Log $C$ for the Reduction of Sulfur. 


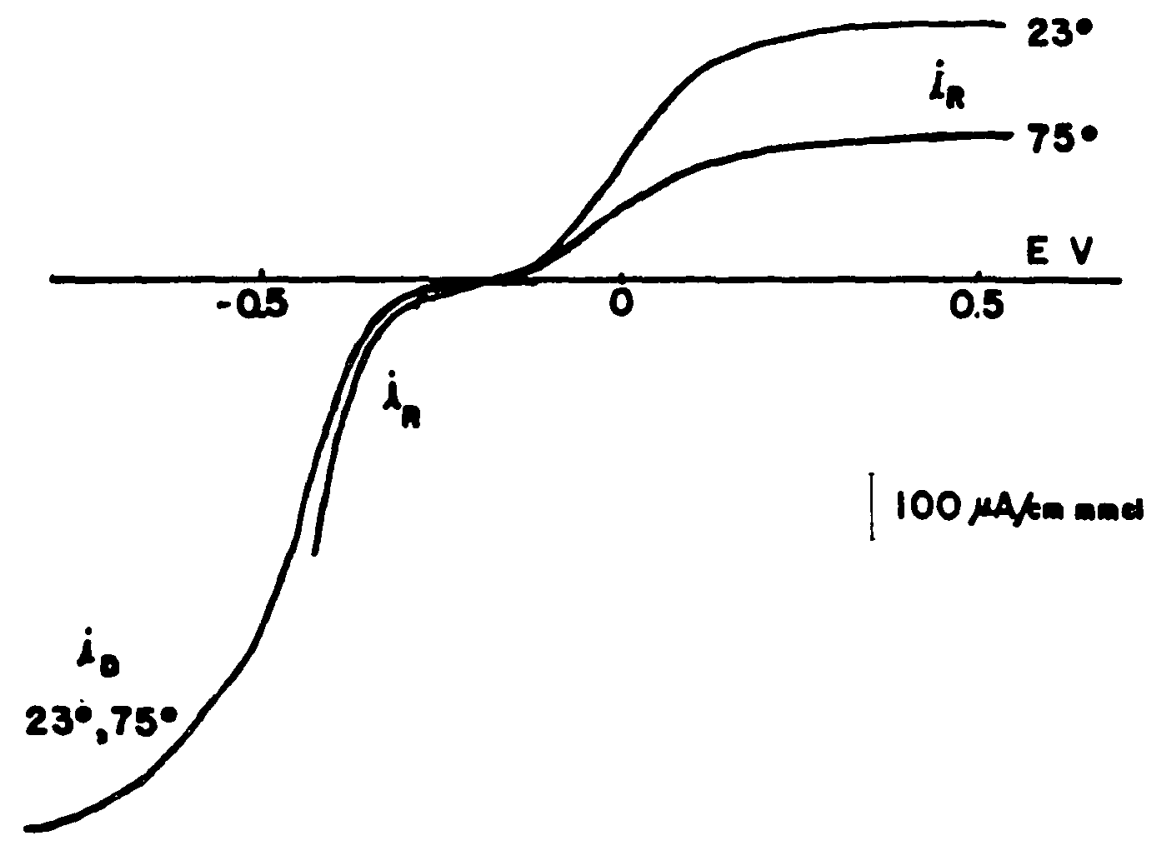

Figure 18. Ring Scans During the Reduction of Sulfur at the Disc Electrode at $23^{\circ}$ and $75^{\circ} \mathrm{C}$. 


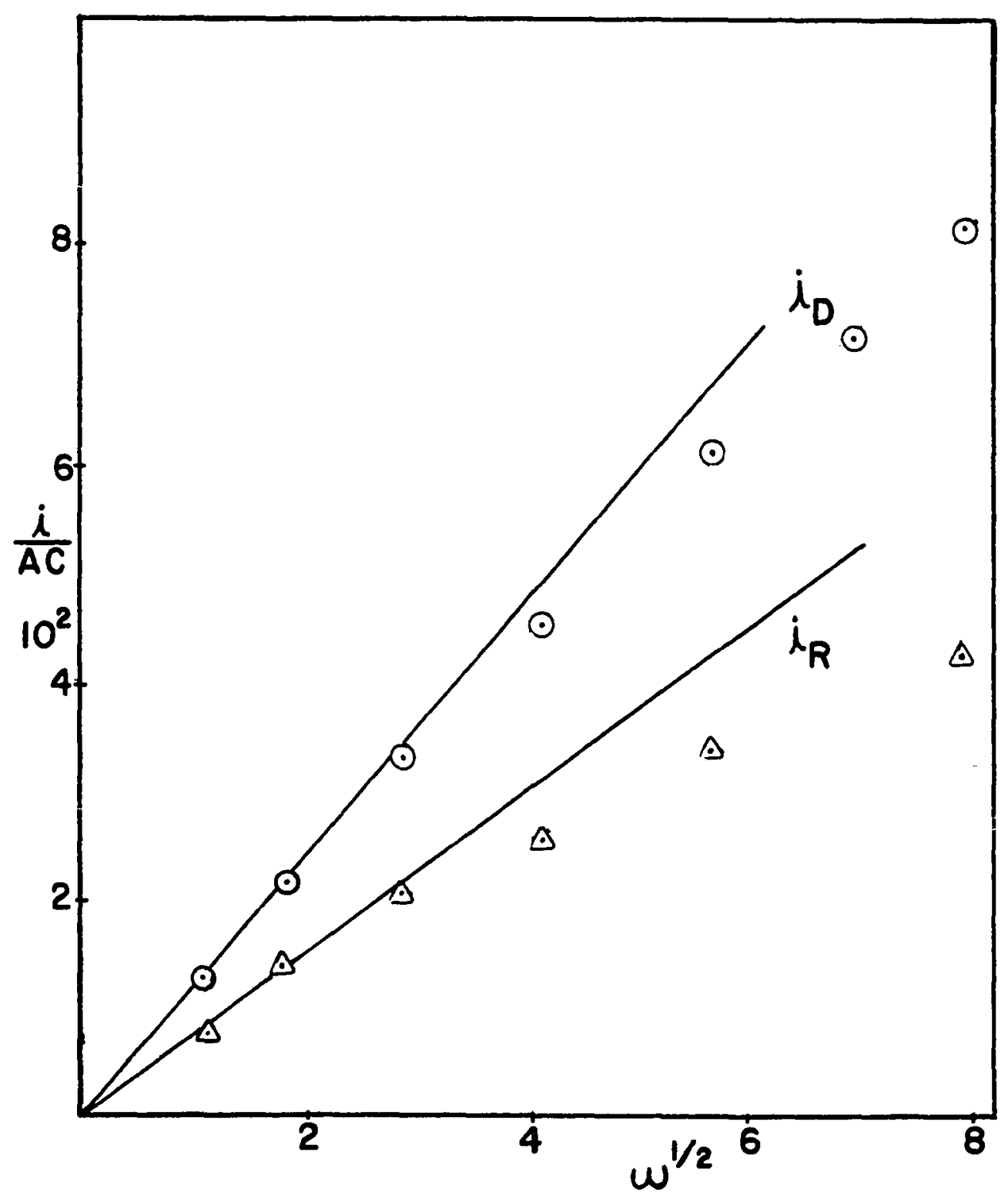

Figure 19. Effect of $w^{\frac{1}{2}}$ on Disc and Ring Currents for Sulfur at $23^{\circ} \mathrm{C}$. 
TABLE VI

HPLC SEPARATION OF SULFUR IN DMSO

\begin{tabular}{ccc} 
Species & $R_{t}(\min )$ & $k^{\prime}$ \\
\hline$S_{6}$ & 1.88 & 0.96 \\
$S_{7}$ & 2.52 & 1.29 \\
$S_{8}$ & 3.96 & 2.02 \\
\hline
\end{tabular}

$\mathbf{S}_{8}$

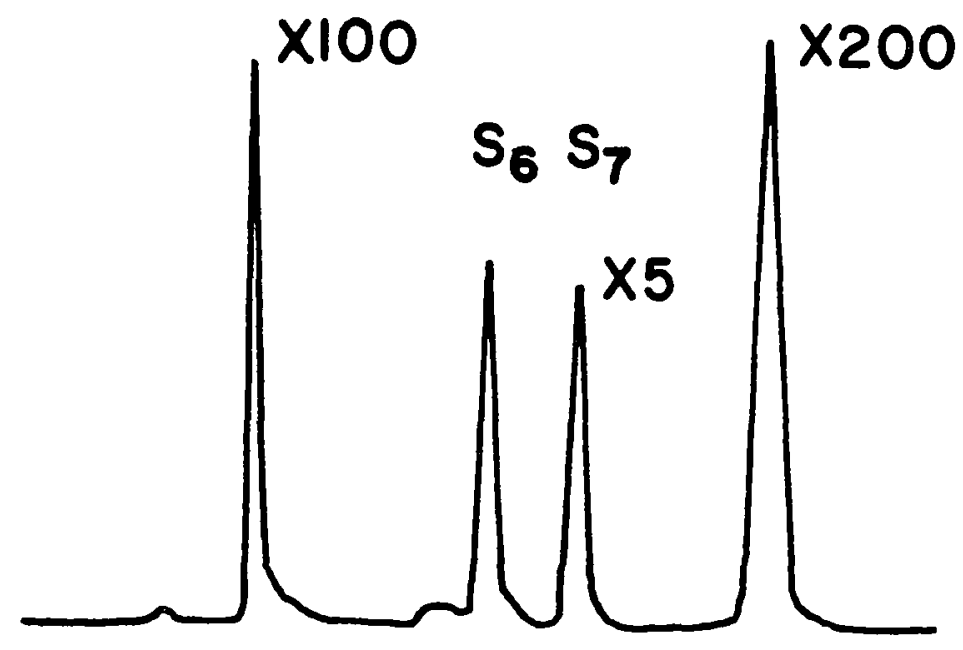

Figure 20. HPLC Separation of Sulfur in DMSO. 
The UV absorbance spectrum for $S_{6}, S_{7}$, and $S_{8}$ were constructed from the chromatogram recorded from the range of 250 to $300 \mathrm{~nm}$. The spectra are shown in Figure 2l. The spectrum for total sulfur was constructed from the summation of different spectra. Electrochemistry of $S_{6}, S_{7}$, and $S_{8}$. Fractions of $S_{6}, S_{7}$, and $S_{B}$ were collected and the electrochemistry of each fraction studied by cyclic voltammetry using a gold microelectrode. Little information was obtained from cyclic voltammetry because of the low concentration of $S_{6}$ and $S_{7}$.

Further studies of the electrochemistry of the sulfur fractions were conducted using the flow cell for the potential range from -0.35 to $-1.60 \mathrm{~V}$ versus $\mathrm{Ag} / \mathrm{AgCl}$. These electrochemical studies showed that the $S_{6}$ and $S_{7}$ fractions are not reduced at the potential range possible, but instead they show small anodic currents as shown in Figure 22. The reduction current-voltage curve for the $S_{8}$ fraction was reconstructed for the potential range studied, and it is shown in Figure 23. 

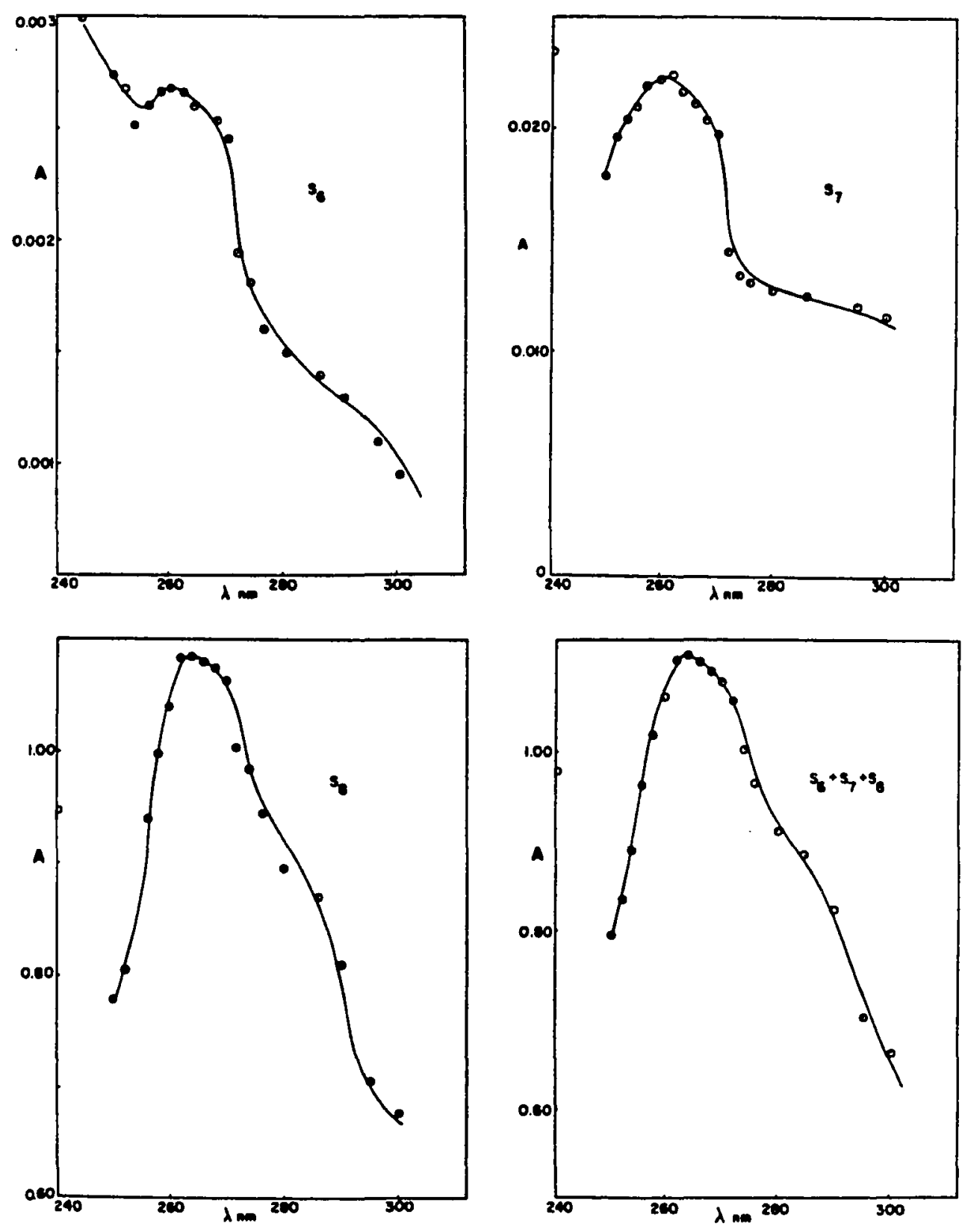

Figure 21. UV Spectra for $S_{6}, S_{7}$, and $S_{8}$ from HPLC Data. 

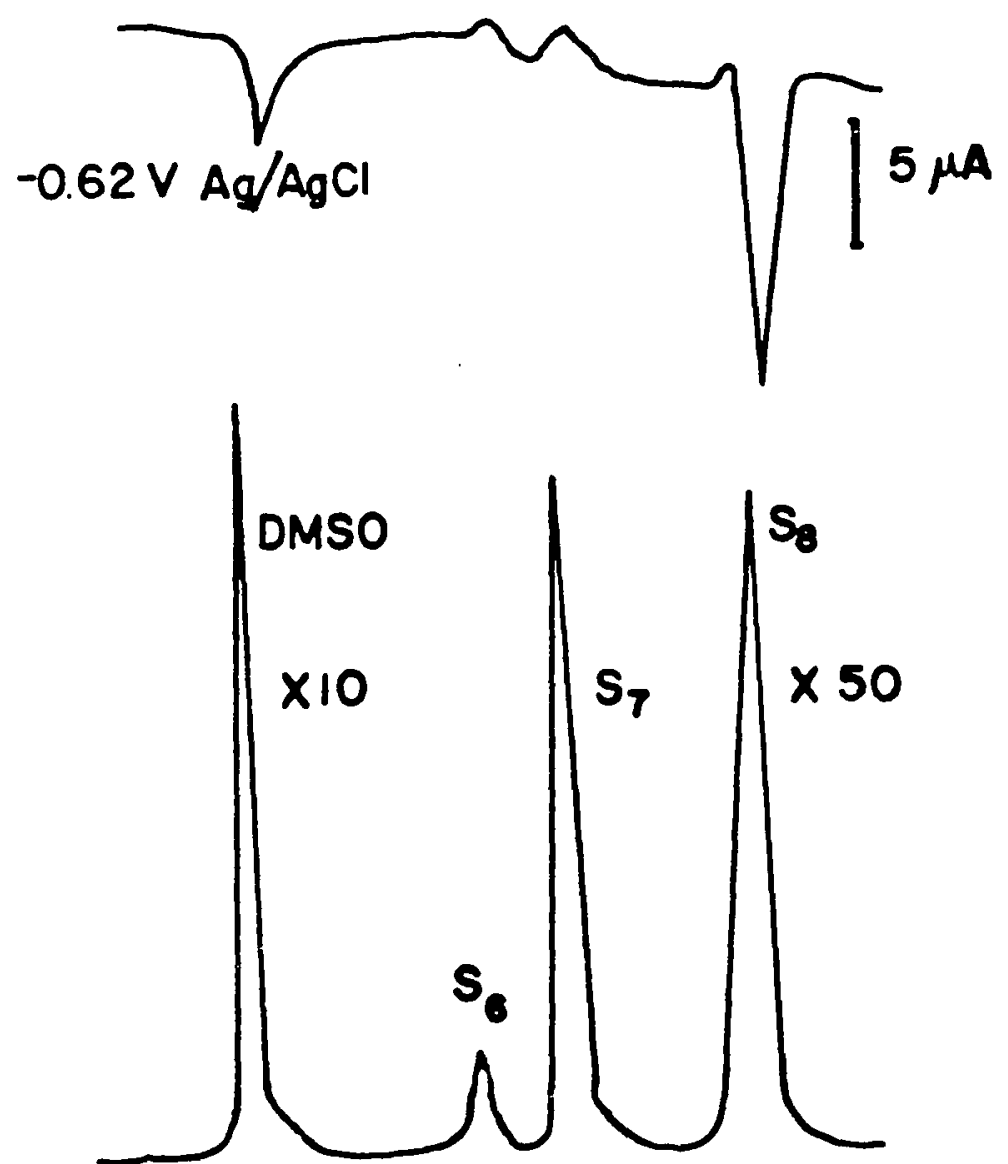

Figure 22. Current-Time Curve for $S_{6}, S_{7}$, and $S_{8}$ in a Flow Cell Compared to the UV Detector Response. 


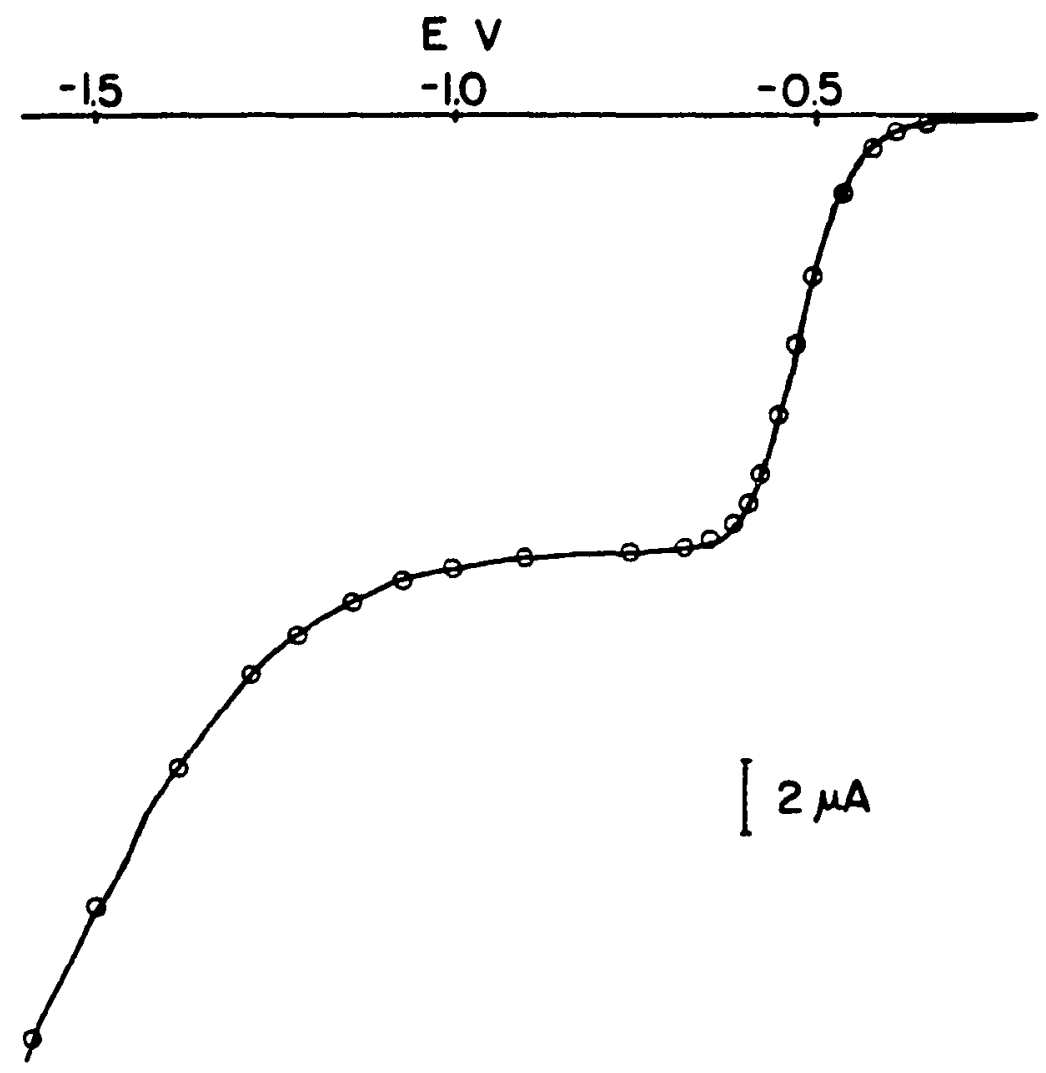

Figure 23. Current-Voltage Curve for the Reduction of $\mathrm{S}_{8}$ in a Flow Cell. 
Reaction of $\mathrm{S}_{\mathrm{x}}$ with metallic cadmium. Freshly precipitated cadmium was reacted with sulfur in DMSO and the reaction followed by HPLC. Typical chromatograms of reactant and product solutions are given in Figure 24. The relative amounts of sulfur before and after the reaction are given in Table VII.

TABLE VII

REACTION OF $S_{x}$ WITH METALLIC CADMIUM

\begin{tabular}{ccccc}
$\begin{array}{c}\text { Total } \\
\text { Sulfur }\end{array}$ & $S_{x}$ & $\begin{array}{c}\text { Before } \\
\text { rxn }\end{array}$ & $\begin{array}{c}\text { After } \\
\text { rxn }\end{array}$ & $\begin{array}{c}\% \\
\text { Change }\end{array}$ \\
\hline $0.5 \mathrm{mF}$ & $S_{6}$ & 0.0021 & 0.0010 & 48 \\
& $S_{7}$ & 0.0017 & 0.0015 & 91 \\
& $S_{8}$ & 1.0500 & 0.9000 & 14 \\
$1.0 \mathrm{mF}$ & $S_{6}$ & 0.0055 & 0.0032 & 41 \\
& $S_{7}$ & 0.0033 & 0.0050 & 85 \\
& $S_{8}$ & 2.0700 & 1.7700 & 14 \\
$2.5 \mathrm{mF}$ & $S_{6}$ & 0.028 & 0.013 & 54 \\
& $S_{7}$ & 0.180 & 0.056 & 67 \\
& $S_{8}$ & 3.800 & 3.420 & 10 \\
\hline
\end{tabular}




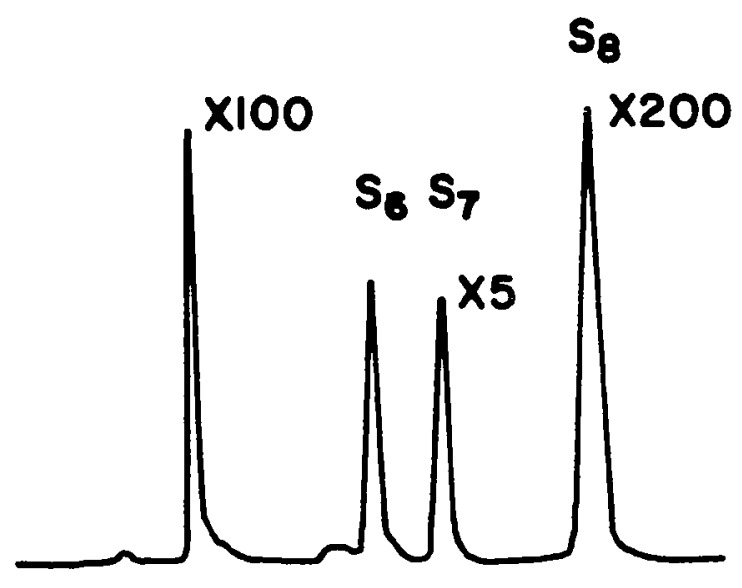

a

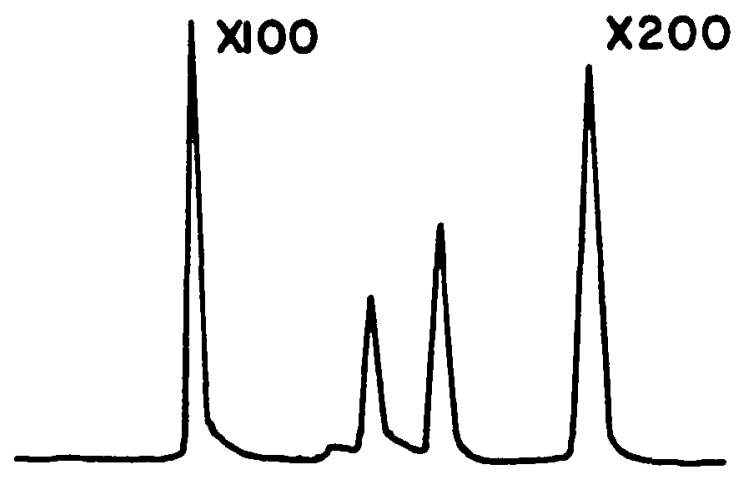

b

Figure 24. HPLC Chromatogram for the Reaction of Sulfur with Cadmium, (a) Before Reaction and (b) After Reaction. 
Cadmium

Electrochemistry. Cadmium (II) in DMSO was reduced at a gold microelectrode and at a RRDE. The reduction is well behaved and shows a characteristic underpotential deposition region at $-0.45 \mathrm{~V}$ versus $\mathrm{Ag} / \mathrm{AgCl}$. Bulk deposition of cadmium starts at $-0.5 \mathrm{~V}$. The anodic peak for the reoxidation of the cadmium monolayer appears at $0.0 \mathrm{~V}$. A typical current voltage curve for the reduction is shown in Figure 25. The diffussion coefficient was calculated to be $1.92 \times 10^{-6} \mathrm{~cm}^{2}$ from the plot $i_{D} / A C$ versus $w^{\frac{1}{2}}$ in Figure 26.

The rate constants for the formation of the cadmium deposits were calculated from the kinetic currents, the results are given in Table VIII.

TABLE VIII

HETEROGENEOUS RATE CONSTANTS FOR THE REDUCTION OF CADMIUM

\begin{tabular}{ccc} 
Temperature $C$ & $D \mathrm{~cm}^{2} \mathrm{sec}^{-1}$ & $\mathrm{k}_{-0.5 \mathrm{~V}} \mathrm{~cm} \mathrm{sec}^{-1}$ \\
\hline 23 & $1.92 \times 10^{-6}$ & 0.0605 \\
50 & $2.66 \times 10^{-6}$ & 0.0693 \\
75 & $2.86 \times 10^{-6}$ & 0.0790 \\
\hline
\end{tabular}

Electrochemical formation of cadmium sulfide and selenide. Electrochemically deposited cadmium was reacted with selenium at potentials close to the underpotential deposition of cadmium. A shift in the anodic peak of cadmium towards more positive poten- 


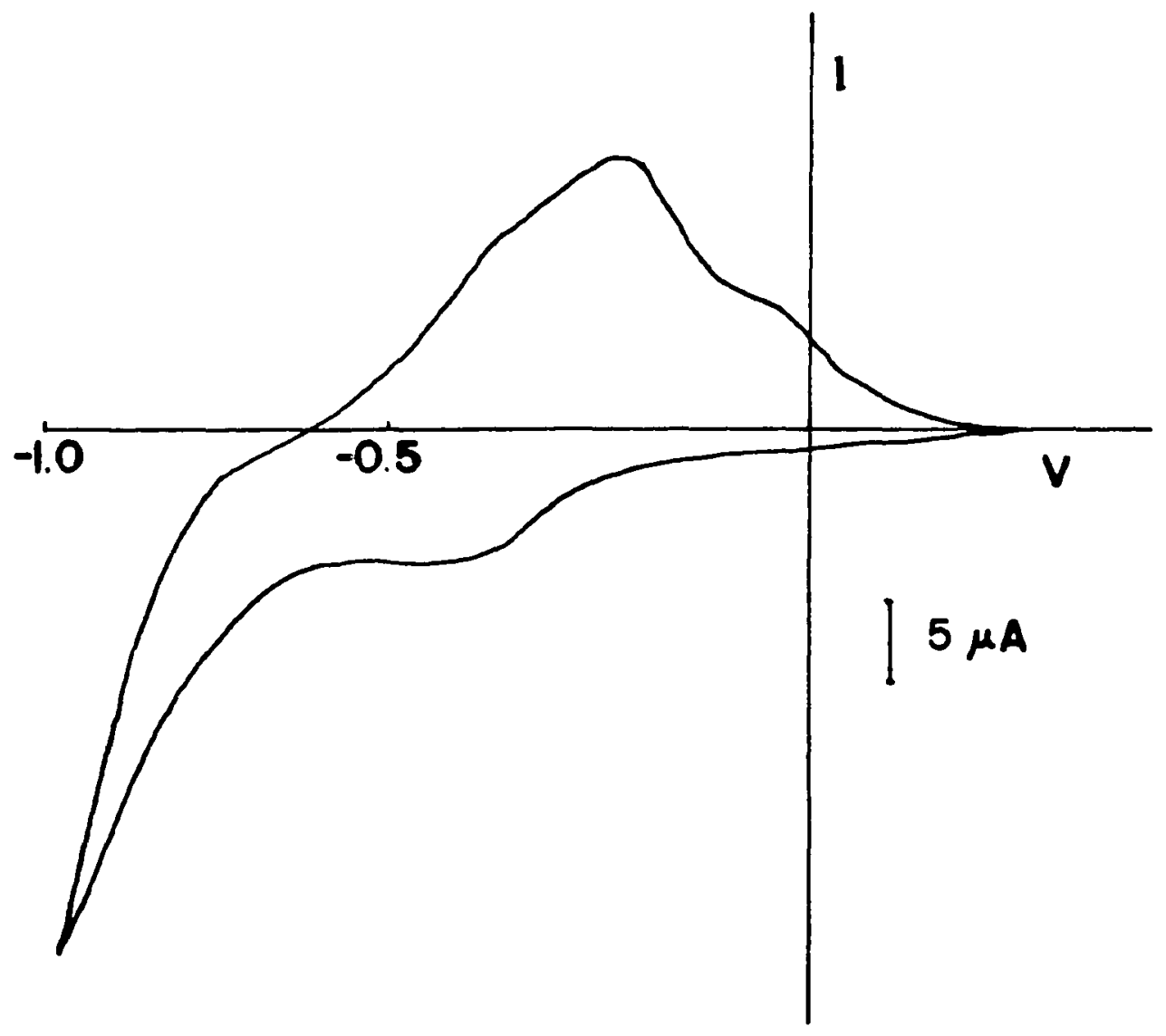

Figure 25. Reduction of Cd (II) at a RRDE at $1000 \mathrm{rpm}$. 


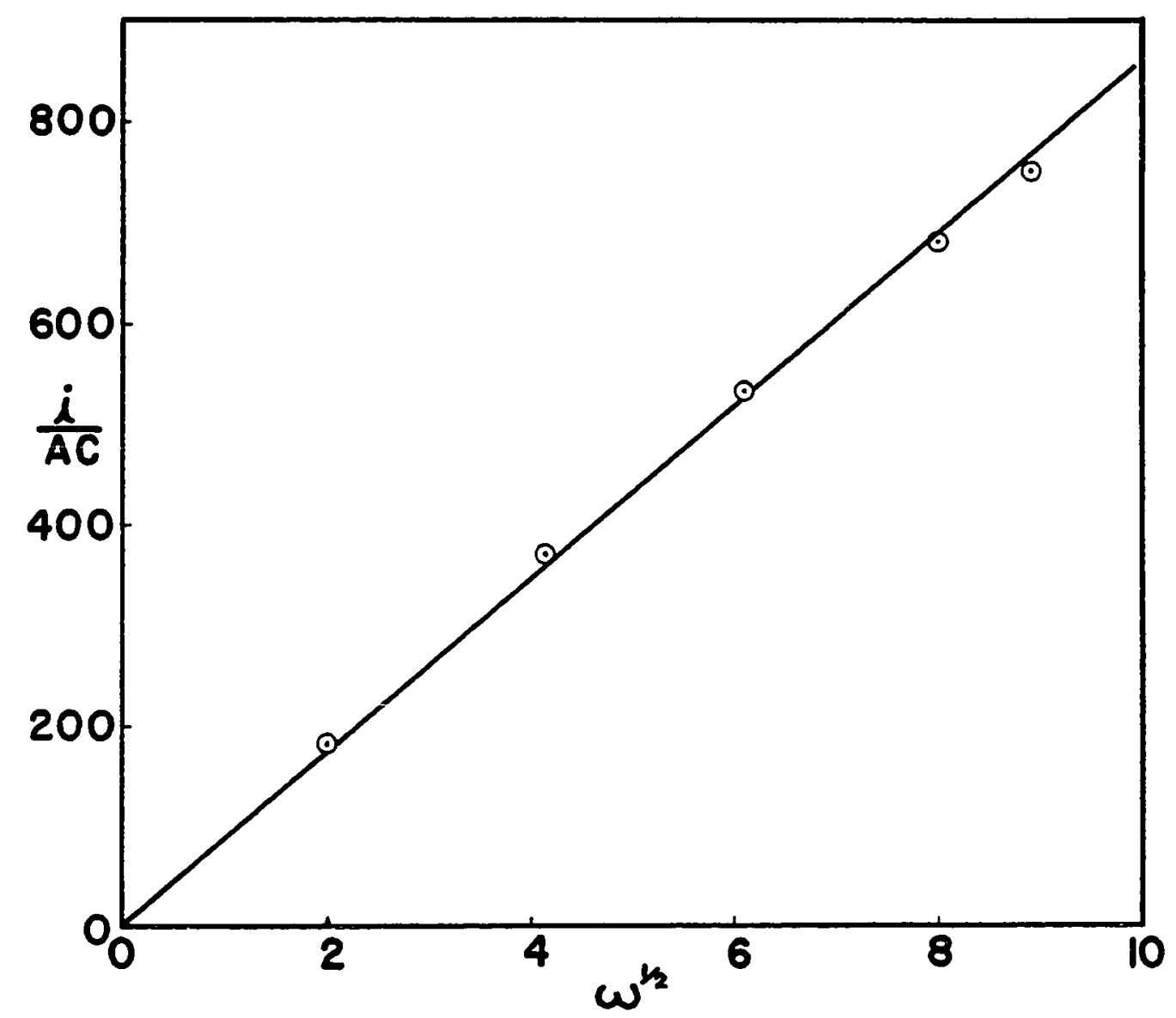

Figure 26. Effect of $w^{\frac{1}{2}}$ on Disc Current $i$ for Cadmium at $23^{\circ} \mathrm{C}$. 
tials was observed while the cathodic peak increase markedly in magnitude. A typical current-voltage curve for this reaction is shown in Figure 27. As larger concentrations of selenium reacts with cadmium, the anodic peak shifts and levels off after all the cadmium has reacted, as seen in Figure 28. The total anodic charge for the striping of the cadmium selenide from the electrode surface also level off indicating the total reaction of the cadmium as shown in Figure 29.

Measurements with the ring electrode at potentials of to.1 and $+0.2 \mathrm{~V}$ shows a single soluble product (Figure 30 ). The concentration of this soluble product decays in the region of the underpotential deposition of cadmium. The observed ring currents, however, are only $20 \%$ of the expected currents. 


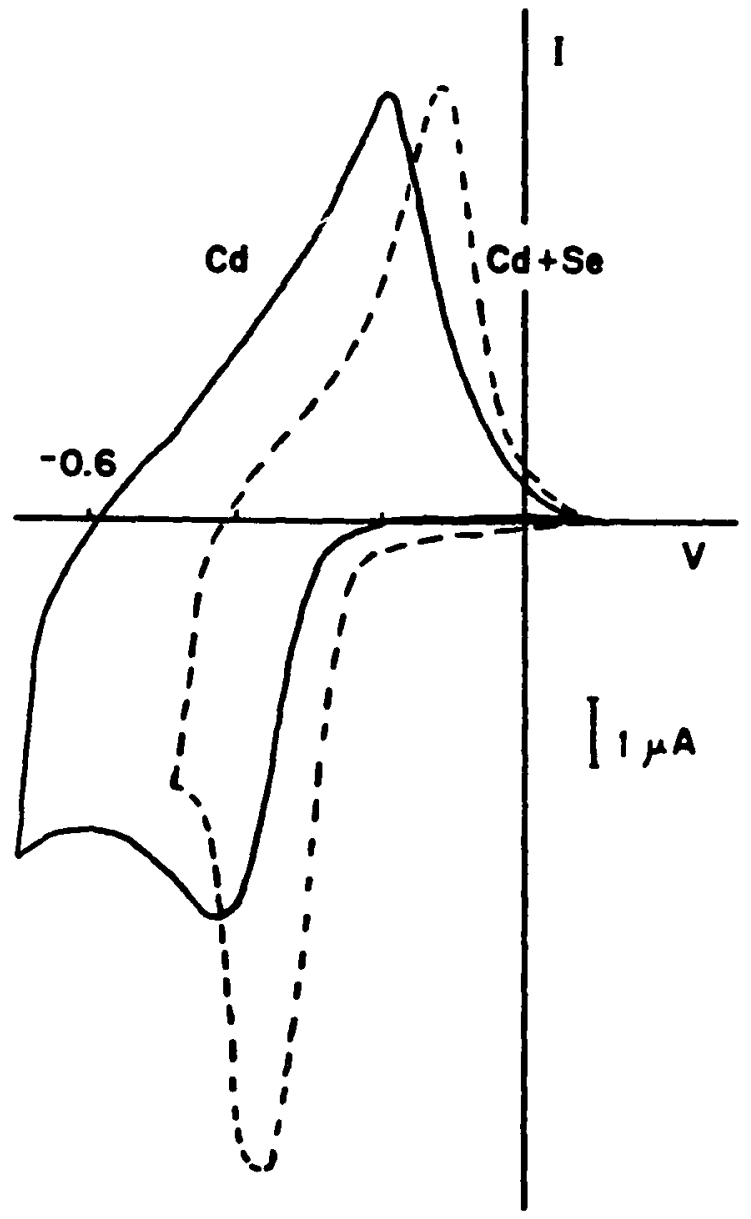

Figure 27. Electrochemical Formation of CdSe. 


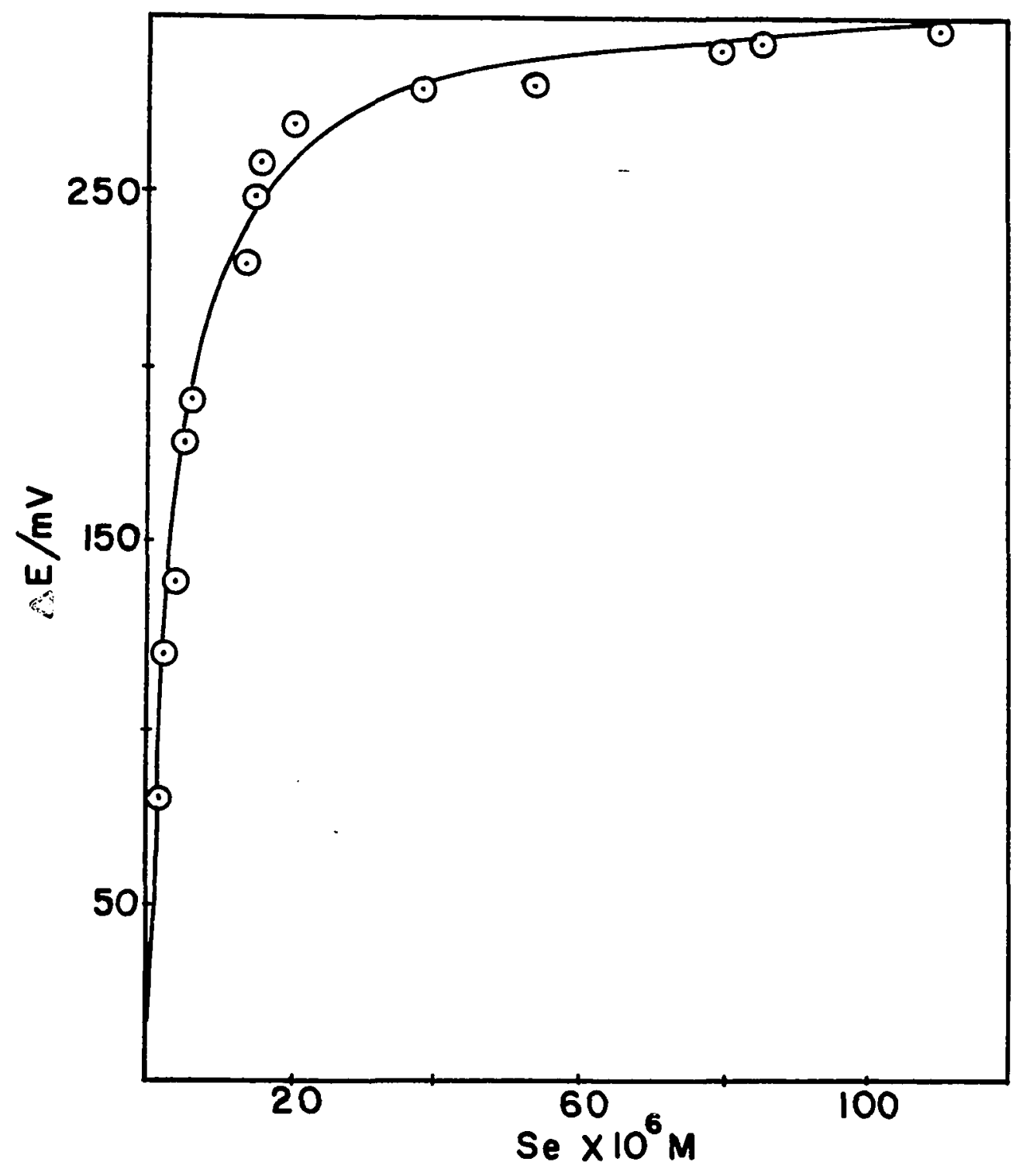

Figure 28. Potential Shift on the Anodic Peak of Cadmium upon Addition of Selenium. 


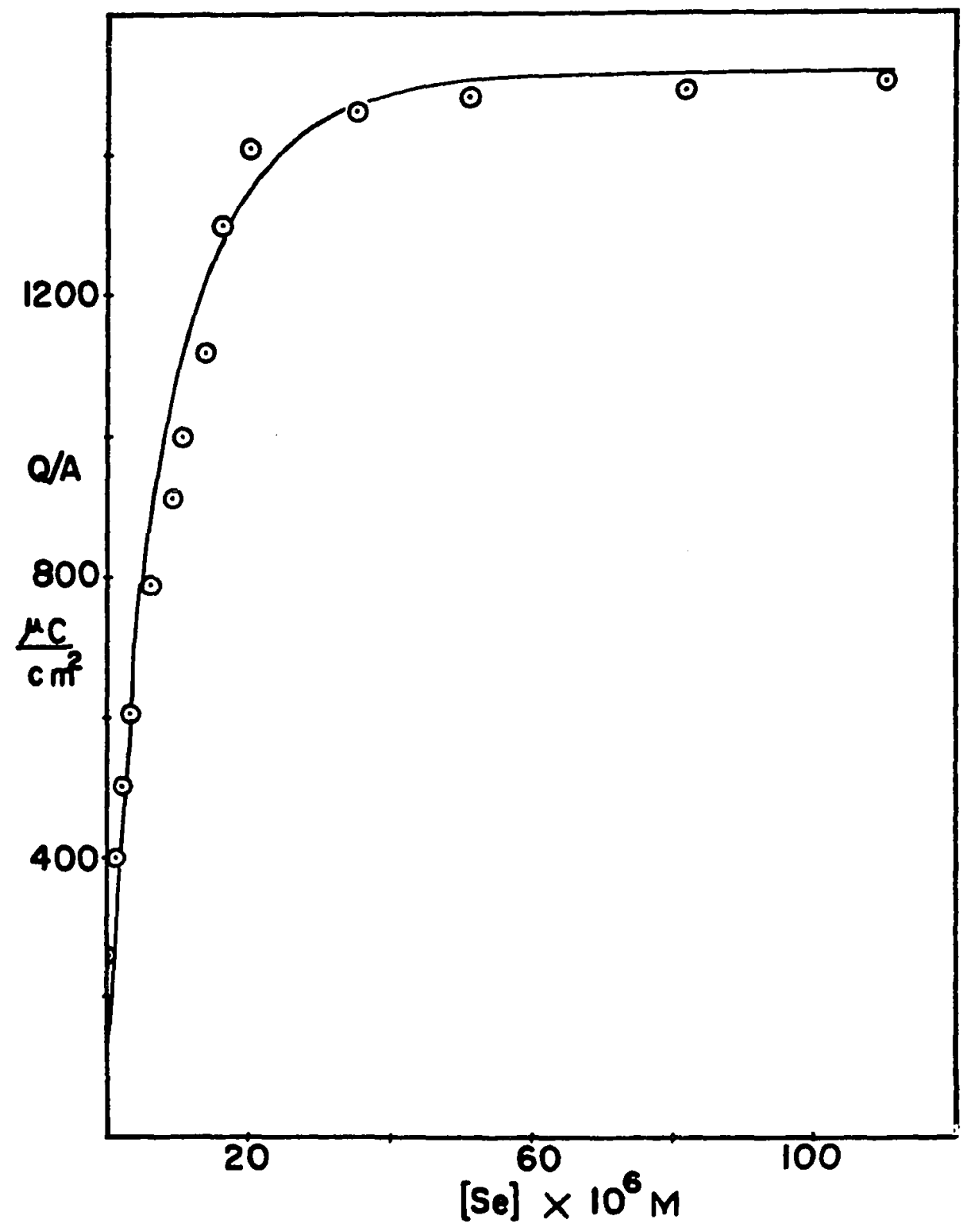

Figure 29. Total Charge in the Stripping of CdS as a Function of Selenium Concentration. 


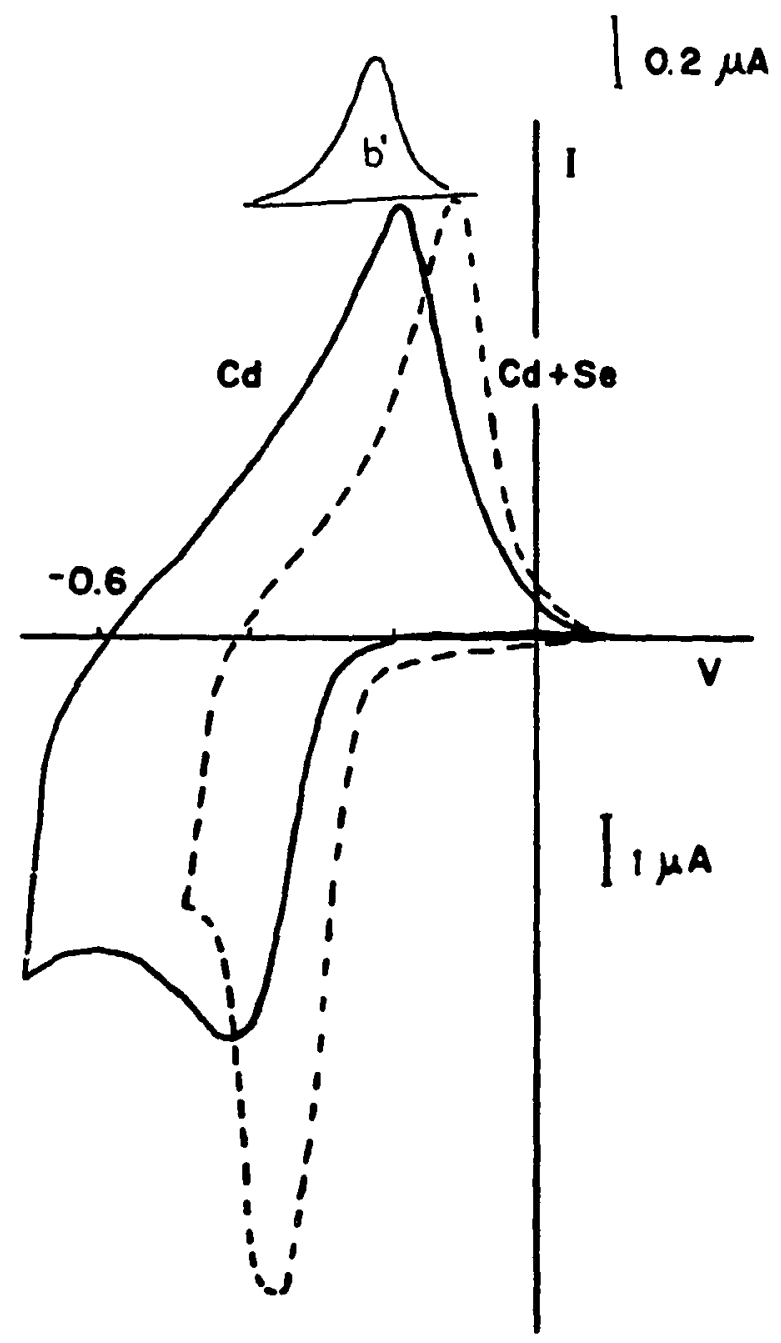

Figure 30. Soluble Products ( $\mathrm{b}^{\prime}$ ) at the Ring Electrode during the Electrochemical Deposition of CaSe at the Disc. 
CHAPTER IV

DISCUSSION

Electrochemical techniques, HPLC, and UV spectroscopy were used to determine the mechanism of the reaction involved in the electrochemical deposition of CaS and CaSe. The overall mechanism was originally proposed by Baranski (31) and Roe (30). From the overall mechanism (eqns. $1,2 a, 2 b, 3 a$, and $3 b$ ) a number of elementary reactions as well as side reactions can also occur. The rates of these side reactions will determine theiv contribution to achieve our goal of producing thin films of controlled stoichiometry, crystallinity and semiconducting properties. The elementary steps studied for these reactions include the kinetics of the electrochemical reduction of cadmium ions, sulfur and selenium molecules, all at a gold RRDE in DMSO solution over a wide range of temperatures and concentrations. Standard heterogeneous rate constants $\left(k^{\circ}\right)$ for the reduction of sulfur and selenium have also been estimated.

Kinetics of the reduction of cadmium ions from DMSO solution at a gold electrode have not been previously reported. At a DME (55), reduction of $\mathrm{Cd}$ (II) appeared to be diffusion controlled. However, the reaction at a gold surface is strongly influenced by surface process. Deposition of cadmium ion from DMSO at a gold RRDE and at a gold microelectrode presented a broad reduction wave in the underpotential deposition region rather than the narrow peak reported by 
Kolb, et al (50) in aqueous solutions. This is probably due to the surface preparation rather than the solvent. The development of the underdeposition potential region suggests the slow restructuring of the gold. Our results of the reduction of cadmium at potentials just negative of the underpotential deposition region showed that this process is very fast $\left(\mathrm{k}_{\mathrm{f}}=0.06 \mathrm{~cm} \mathrm{~s}^{-1}\right)$ indicating that charge transfer to $\mathrm{Cd}(\mathrm{II})$ is not expected to inhibit the rate of the overall process of deposition of CdS and CaSe.

It has been noted (30) that on a CaS surface, deposition of $\mathrm{Cd}(\mathrm{II})$ has a considerable overpotential compared to deposition on gold or cadmium. There are two reasons for this: nucleation and resistance of the CdS film. Once the nucleation barrier is overcome further deposition proceeds rather rapidly. The presence of sulfur helps to decrease the nucleation potential (30).

Selenium presents very similar results to those of sulfur. Effects on the underpotential region of cadmium due to the presence of selenium were evident even at a Se/Cd ratio of 0.00125 in $\mathrm{RRDE}$ measurements. A positive shift up to $300 \mathrm{mV}$ (Figure 28) in the anodic peak was observed when selenium was added, while the cathodic peak showed a shift not larger than $40 \mathrm{mV}$. Ratios of Se/Cd higher than 0.1 did not shift the anodic peak any further.

The reoxidation of a single soluble product was observed at the ring $\left(E_{r}=+0.4\right)$ when the selenium and cadmium reacted (see Figure 30 ). This stable intermediate is perhaps due to the oxidation of polyselenides and possibly also dissolved CaSe and its complexes. A similar product was reported (30) during the formation of CaS. 
Electrochemical characteristics of sulfur, as well as selenium in DMSO are in sharp contrast to that of cadmium. One of the most unusual observations is that from the three sulfur rings present in solution, $S_{6}, S_{7}$, and $S_{8}$, only $S_{8}$ is reducible at a gold electrode while $S_{6}$ and $S_{7}$ appear to absorb strongly on the electrode surface. HPLC separation of these and higher rings compounds has been documented by two research groups $(40,41)$ using a UV absorbance detector. However, electrochemical detectors have not been previously used with sulfur or selenium. Figure 22 shows the response of the $\mathrm{UV}$ and electrochemical detectors in series showing unequivocally the lack of electrochemical response of $S_{6}$ and $S_{7}$ on a gold electrode. A complete current potential curve for $S_{8}$ was compiled from a series of individual injections and a series of potentials. A comparison of the results in Figure 23 with the RRDE curves of sulfur in DMSO, as shown in Figure 13, indicates without a doubt that $S_{8}$ is the species that is responsible.

Electrochemical studies reported in the literature $(48,49)$ as well as those reported in the experimental section refer to $S_{8}$ which is of course, the major species present in solution. Although small, perhaps depending on the method of preparation of the solution, variable amounts of $S_{6}$ and $S_{7}$ are usually present (40). Therefore it is customary to identify sulfur solutions as consisting of $\mathrm{S}_{8}$ molecules and hence to calculate the concentration on the basis of this molecule. Even though $S_{8}$ certainly determines the observed electrochemical behavior, such as reduction potential and rate of charge transfer, it is also interesting to propose what the role of $S_{6}$ and $S_{7}$ might be. 
There are two experimental observations that are relevant to the electrochemical role of $S_{6}$ and $S_{7}$. First it was noted that cathodic currents decrease with successive scans. This decrease was not caused by oxygen diffusing into the solution and reacting with the products, although the reaction products are sensitive to oxygen. Periodic cleaning of the gold electrode was needed to obtain reproducible results, especially at elevated temperatures. This cleaning operation could be accomplished by applying a positive potential or by removing the electrode and polishing with fine alumina. A definite surface reaction occurred since a brown film was formed on the electrode surface.

To verify if the decrease in current was indeed due to a kinetic process or not, the electrode was repolished and the high rotation rate measurements were made first. The observed currents were lower than those expected, indicating that indeed the decrease was due to a kinetic process and not to film formation.

Secondly, from the HPLC chromatograms $S_{6}$ and $S_{7}$ are not reduced but instead the current-time curve shows anodic peaks at all potentials from -0.5 to $-1.6 \mathrm{~V}$. These observations suggest that $S_{6}$ and $S_{7}$ react with a gold surface to produce a very stable absorbed layer or surface compound. Gold is negatively charged relative to the solution in the potential range studied, and the formation of a surface compound that involves no apparent net current for its formation can cause an external current by a change in the double layer structure. That is, formation of a Au-S layer causes the reorientation of the dipoles (methanol molecules in the HPLC experiment) and change in the ionic 
composition of the outer Helmholtz plane.

Barlett (56), some years ago, and recently others (57) noted that $S_{6}$ and $S_{7}$ are much more reactive than $S_{8}$ in some homogeneous reactions. In a sense this is also true for the electrochemical behavior, not in terms of reduction but in terms of surface absorption.

The spectrum of $\mathrm{S}$ saturated vapor recorded below $250^{\circ}$ by Bass (52) consist of unresolved maxima at 210,265, and $285 \mathrm{~nm}$. This compares well with the absorption spectrum of $S_{8}$ in nonpolar solvents, as well as in DMSO at $25^{\circ} \mathrm{C}$. Furthermore, the spectrum is in agreement with the spectrum reconstructed from HPLC data. The $S_{6}$ and $S_{7}$ spectra were constructed from the absorbance of the $S_{6}$ and $S_{7}$ fractions from HPLC. The $S_{6}$ spectra show a resolved shoulder at $260 \mathrm{~nm}$. Previous studies (53) in ethyl ether at $25^{\circ} \mathrm{C}$ did not show a resolved peak. The $S_{7}$ spectrum has not been reported in the literature. Molar absorptivity coefficients were not calculated because no information on the concentrations of $S_{6}$ and $S_{7}$ was available from the experiment.

$\mathrm{S}_{8}$ showed two well defined reduction waves at $(-0.6,-1.1 \mathrm{~V}$ versus $\mathrm{Ag} / \mathrm{AgCl}$ ) at a $\mathrm{RRDE}$ and at a gold microelectrode for concentrations under saturation. These results are consistent with similar studies previously reported for nonaqueous solution (36, 47-49). The first reduction wave of sulfur showed some curvature (Figure 15) for plots of $i_{D}$ versus $w^{\frac{1}{2}}$ at the RRDE, which suggests some kinetic complication. Bonaterre $(36)$ has also suggested this behavior. Paris and Plichon (49) reported that there are no kinetic complications but, their studies covered only a small rotation rate rangs. The 
observed standard heterogeneous rate constants for the reaction given in Table $\mathrm{V}$ indicate moderate charge transfer rates for the temperatures studied. The transfer coefficient was equal to $0.52 \pm 0.04$ over the potential range of -0.2 to $-0.8 \mathrm{~V}$, for all temperatures which indicates symmetry in the activation barrier.

Smaller ring currents than those predicted from the collection efficiency suggest a following reaction after the electron transfer. This could also be inferred from the shape of the oxidation curves, which show a slow rise rather than a steep rise. As the temperature is increased the following reaction is more obvious (Figure 18). Electrochemistry of selenium is very similar to that of sulfur. Selenium solutions in DMSO also consist of $\mathrm{Se}_{6}, \mathrm{Se}_{7}$, and $\mathrm{Se}_{8}$ rings, as shown in our HPLC studies and other works previously reported in $\mathrm{CS}_{2}$ (41). Electrochemical reactivity for the different selenium fractions could not be determined due to their small concentrations. From the reaction of metallic cadmium and selenium solutions (Table III), it is apparent that $S_{6}$ and $S e_{7}$ will be more reactive than $\mathrm{Se}_{8}$. However, $\mathrm{Se}_{6}$ and $\mathrm{Se}_{7}$ may be adsorbed on the cadmium or the electrode surface. The reduction of selenium also presents a kinetic step in the charge transfer, as shown from plots $i_{D}$ versus $w^{\frac{3}{2}}$ (Figure 8 ). Standard heterogeneous rate constants showed that this reaction is slower than that of sulfur. The formation of a film on the electrode surface was also observed but it does not appear to affect the kinetic process. While the composition of the film was not investigated, it is reasonable to assume the formation of a Au-Se surface compound. 
Solubility of selenium in DMSO was found to be $4.3 \times 10^{-5} \mathrm{~F}$. at room temperature, and increasing with temperature as shown in Figure 5. Addition of sulfur in concentrations up to $0.25 \mathrm{mF}$. enhanced the solubility of selenium, perhaps due to the formation of $\mathrm{Se}_{6} \mathrm{~S}_{2}$ or $\mathrm{Se}_{4} \mathrm{~S}_{4}$ as calculated from the slopes of the curves in Figure 6. A new peak in the HPLC separation of sulfur-selenium mixtures (Figure 31) with a capacity factor equal to 2.96 indicates the formation of $\mathrm{Se}_{5} \mathrm{~S}_{3}$, according to Steudel (42).

Bartlett $(58,59)$ proposes that $S_{8}$ is nucleophilically attacked by $\mathrm{CN}^{-}$to form $\mathrm{SCN}^{-}$or by triphenylphosphine to form $\left(\mathrm{C}_{6} \mathrm{H}_{5}\right)_{3} \mathrm{PS}$. These reactions open the sulfur rings. According to this view the successive reactions of triphenylphosphine or $\mathrm{CN}^{-}$with sulfur, and with the intermediate products, are nucleophilic displacement. reactions. Once the sulfur ring is opened, the remaining chain is further attacked by $\mathrm{CN}^{-}$or triphenylphosphine until the chain is completely consumed. In the formation of CaS or CaSe this may be the process, with the electrode surface acting as a nucleophile to open the sulfur ring.

In summary, from our results it is clear that cadmium deposition is not the limiting factor in the reaction of formation of CdS and Case. The reaction of $S_{8}$ with cadmium is slow and the reaction with selenium is even slower. Adsorption of $S_{6}$ and $S_{7}$ on the surface will produce deposits of CdS with excess sulfur, which are not as good material for phoelectrochemical cells. 

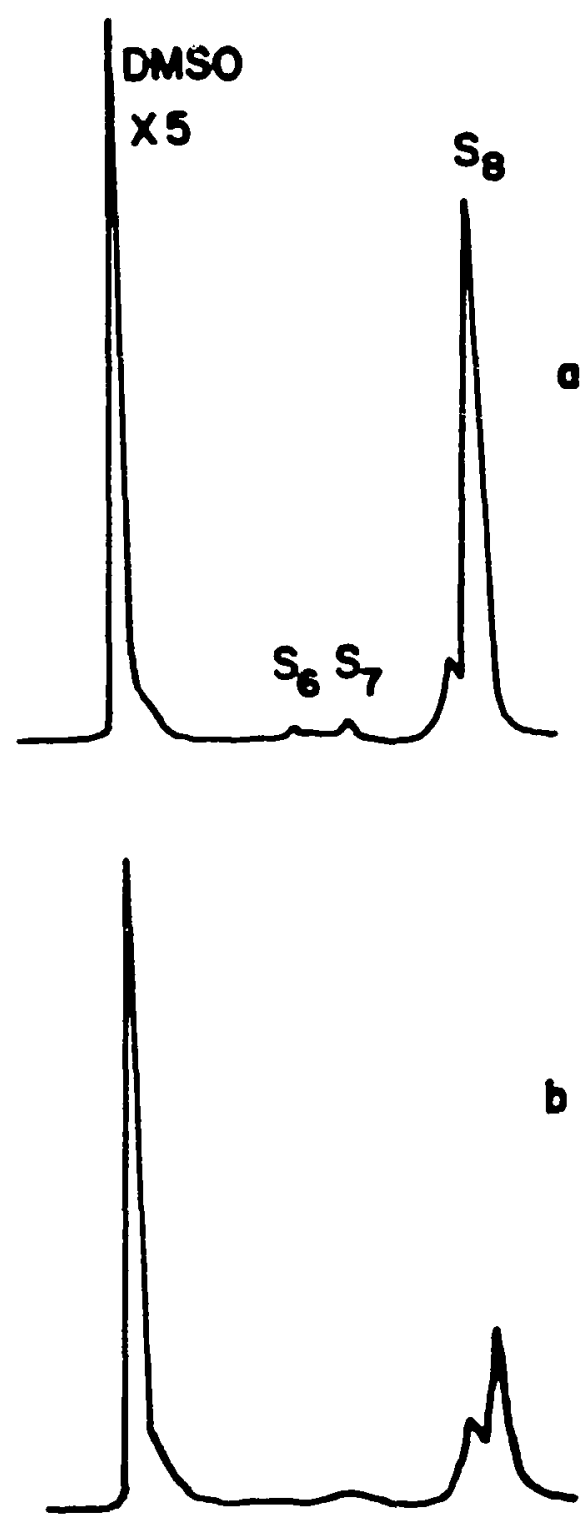

Figure 31. HPLC Separation of a Mixture of Saturated Selenium and Sulfur $1 \times 10^{-7} \mathrm{~F}$. in DMSO. 
REFERENCES

1. A. Heller, Solar Energy 29, 153 (1982); and B. Miller, Electrochim. Acta, 25, 29 (1980).

2. H. Gerischer, J. Electroanal. Chem. Interfacial Electrochem., 58, $263(1975)$.

3. A.B. Ellis, S. W. Kaiser, and M. S. Wrighton, I. Am. Chem. Soc., 99 2939 (1977); Ibid 98, 6855 (1977).

4. K. Rajeswar, P. Sing, and J. Dubow, Electrochim. Acta, 23, 1117 (1978).

5. T. S. Jayadeviah, Appl. Phys. Lett., 25, 399 (1974).

6. A. J. Nozik, Ann. Rev. Phys. Chem., 29. 189 (1978).

7. A. T. Fahrenbruch, J. Cryst. Growth, 39, 73 (1977)

8. M. A. Russak, J. Reichman, H. Witzke, S. K. Deb, and S. N. Chen, I. Electrochem. Soc., 127, 725 (1980).

9. J. W. Sheroham. I. Electrochem. Soc., 128, 1817 (1981).

10. K. L. Chopra, D. K. Pandya, and R. C. Kainthla, J. Electrochem Soc., 127,277 (1980).

11. R. A. Boudreau and R. D. Rauh, J. Electrochem. Soc., 130, 513 (1983).

12. D. R. Pratt, M. E. Langmuir, R. A. Boudreau, and R. D. Rauh, I. Electrochem. Soc., 128, 1627 (1981).

13. I. Kaur, D. K. Pandya, and K. L. Chopra, I. Electrochem Soc., 127, 943 (1980).

14. G. A. Kitaer and T. S. Tarekhova, Russ. J. of Inorg. Chem., 15, 25 (1970).

15. T. H. Weng, J. Electrochem. Soc., 117, 725 (1970); Ibid, 126, 1820 (1979). 
16. B. Miller, A. Heller, M. Robbings, S. Menezes, K. C. Chang and J. Thomson Jr., J. Electrochem. Soc., 124, 1019 (1977).

17. A. M. Redon, J. Electrochem. Soc., 127, 2023 (1980).

18. M. Neuman and K. Kalyanasundaram, Ber. Bunsenges. Phys. Chem., 85, 1112 (1981).

19. G. Hodes, J. Manassen, and D. Cahen, J. Electrochem. Soc., 127, $2252(1980)$.

20. Xu-Rui Xiao, and H. Ti Tien, J. Electrochem. Soc., 130, 55 (1983).

21. G. Hodes, J. Manassen, and D. Cahen, Nature, 262, 403 (1976).

22. G. Hodes, J. Manassen, and D. Cahen, J. Electrochem. Soc., 125, 1623 (1978).

23. B. Miller and A. Heller, Nature, 262, 680 (1976).

24. B. Miller and M. S. Kazacos, J. Electrochem. Soc., 127, 2378 (1980) and references therein.

25. H. Gobrecht, H. D. Liess, and A. Tausend, Ber. Bunsenges. Phys. Chem., 67, 930 (1963).

26. M. P. R. Panicker, M. Knaster, and F. A. Kroger, J. Electrochem. Soc. , 125, 566 (1978).

27. M. Tomkiewics, I. Ling, and W. S. Parsons, J. Electrochem. Soc., 129,2016 (1982).

28. G. P. Power, D. R. Peggs, A. J. Parker, Electrochim. Acta, 26, 681 (1981).

29. Y. Ueno, H. Minoura, T. Nishikawa, and M. Tsuiki, J. Electrochem. Soc., 130, $43(1983)$.

30. D. K. Roe, I. Wenzhao, and H. Ferischer, J. Electroanal. Chem., 136, 323 (1982).

31. A. S. Baranski and W. R. Fawcett, J. Electrochem. Soc., 127, 766 (1980).

32. A. S. Baranski, W. R. Fawcett, A. MeDonald, R. M. DeNobriga, and J. R. McDonald, J. Electrochem. Soc., 128, 963 (1981).

33. A. S. Baranski, W. R. Fawcett, K. Gatner, A. C. McDonald, J. R. McDonald, and M. Selen. J. Electrochem, Soc., 130, 579 (1983).

34. H. Hogle, Master's Thesis, Portland State University, Portland, Oregon, 1982. 
35. C. K. Mann and K. K. Barnes, "Electrochemical Reactions in Nonaqueous Solvents", Marce; Dekker, New York, 1970, chapter 14.

36. J. Badoz-Tambling, R. Bonnaterre, G. Cauquis, M. Delmar, and G. Demage, Electrochim. Acta, 21, 119 (1976), and references therein.

37. W. Giggenbach, Inorg. Chem., 11, 1201 (1972).

38. W. Giggenbach, Inorg. Chem., 10, 1306 (1971).

39. R. Steudel, "Topics in Current Chemistry \#102, Homocyclic Sulfur Molecules", F. L. Boschke, Ed., Berlin, GDR, 1982.

40. F. N. Tebbe, E. Wasserman, W. G. Peet, A. Vatvars, and A. C. Hayman, I. Am. Chem. Soc., 104, 4971 (1982).

41. R. Steudel and E. M. Strauss, Z. Naturforsch., 36b, 1985 (1981).

42. R. Steudel and R. Laitinen, "Topics in Current Chemistry, \#102, Cyclic Selenium Sulfides", F. L. Boschke, Ed., Berlin, GDR, 1982.

43. A. N. Frumkin and L. N. Nekrasov, Dokl. Akad. Nauk. SSSR, 126, 115 (1959).

44. A. N. Frumkin, L. N. Nekrasov, V. G. Levich, and Y. B. Ivanov, J. Electroanal. Chem., 1, 84 (1959).

45. V. G. Levich, Acta Physiocochim. URSS, 17, 257 (1942).

46. W. J. Albery and M. L. Hitchman, "Ring-Disc Electrodes". Oxford University Press, London, 1971, p 17.

47. T. Fujinaga, T. Kuwamoto, S. Okazaki, and M. Hojo, Bull. Chem. Soc. Jpn., 53, 2851 (1980).

48. D. T. Sawyer, R. P. Martin, W. H. Doub, and J. L. Roberts, Inorg. Chem., 12, 1921 (1973).

49. J. Paris and V. Plichon, Electrochim. Acta, 26, 1823 (1981).

50. J. W. Shultze, F. D. Koppitz, and M. M. Lohrengel, Ber. Bunsenges. Phys, Chem., 78, 693 (1974).

51. D. M. Kolb, M. Przasnyki, and H. Gerischer, J. Electroanal. Chem., 54, 25 (1974).

52. A. M. Bass, J. Chem. Phys., 191291 (1953).

53. B. Meyer, M. Gouterman, D. T. Oomen, K. Spitzer, and T. StroyerHansen, "Sulfur Research Trends", R. F. Gould, Ed., New York, $1972, \mathrm{p} 53$. 
54. G. J. Janz and R. P. T. Tomkins, "Nonaqueous Electrolytes Handbook", Academic Press, 1972.

55. D. L. McMasters, R. B. Dunlap, J. R. Kuempel, L. W. Kreider and T. R. Shearer, Anal. Chem., 39, 103 (1967).

56. P. D. Bartlett, G. Lohaus, and C. D. Weis, J. ․․․ Chem. Soc., $\underline{83}$, 103 (1961).

57. R. Steudel, "Chemistry of the Non-Metals" W. de Gruyter: New York, 1977, p. 208.

58. A. J. Bard and L. R. Faulkner, "Electrochemical Methods. Fundamentals and applications" John Wiley \& Sons. New York (1980), p. 290. 